\title{
Impact of the $2^{\circ} \mathrm{C}$ target on global woody biomass use
}

\author{
Pekka Lauri, ${ }^{1, *}$ Nicklas Forsell, ${ }^{1}$ Anu Korosuo ${ }^{1}$, Petr Havlík ${ }^{1}$, Michael Obersteiner ${ }^{1}$, Annika \\ Nordin $^{2}$ \\ 1) International Institute for Applied Systems Analysis (IIASA), Schlossplatz 1, A-2361 Laxenburg, Austria \\ 2) Swedish University of Agricultural (SLU), Umeå, Sweden \\ *) Corresponding author, pekka.lauri@iiasa.ac.at
}

\begin{abstract}
In this study we investigate the implications of reaching the $2^{\circ} \mathrm{C}$ climate target for global woody biomass use by applying the Global Biosphere Management Model (GLOBIOM) and the recently published SSP-RCP scenario calculations. We show that the higher biomass demand for energy needed to reach the $2^{\circ} \mathrm{C}$ target can be achieved without significant distortions to woody biomass material use and that it can even benefit certain forest industries and regions. This is because the higher woody biomass use for energy increases the demand for forest industry by-products, which makes forest industry final products production more profitable and compensates for the cost effect of increased competition over raw materials. The higher woody biomass use for energy is found to benefit sawnwood, plywood and chemical pulp production, which provide large amounts of by-products, and to inhibit fiberboard and mechanical pulp production, which provide small amounts of by-products. At the regional level, the higher woody biomass use for energy is found to benefit material production in regions, which use little roundwood for energy (Russia, North-America and EU28), and to inhibit material production in regions, which use large amounts of roundwood for energy (Asia, Africa and South-America). Even if the $2^{\circ} \mathrm{C}$ target increases harvest volumes in the tropical regions significantly compared to the non-mitigation scenario, harvest volumes remain in these regions at a relatively low level compared to the harvest potential.
\end{abstract}

\section{Introduction}

Biomass is an important factor in reaching the $2^{\circ} \mathrm{C}$ climate target, as it provides a costefficient way to replace fossil fuels in energy production. Historically the most important source of biomass use for energy has been woody biomass (Fernandes et al. 2007). Currently about half of harvested woody biomass is used for energy production (FAO 2016).

Consequently, the higher biomass demand for energy needed to reach the $2^{\circ} \mathrm{C}$ target is expected to increase woody biomass use significantly in the future and tends to lead to more intensive forest resources use. More intensive forest resources use raises concerns about the increasing disturbance of natural forests, higher woody biomass prices, and decreasing woody biomass availability for material use.

The future biomass use for energy has been studied extensively by integrated assessment models, which predict that reaching the $2{ }^{\circ} \mathrm{C}$ target requires a $20-50 \%$ biomass share of primary energy in 2100 (200-450 EJ/year) while the current biomass share of primary energy is about 10\% (54 EJ/year) (Rose et al. 2014, IIASA 2016). These models do not usually include an explicit biomass sector module, but utilize biomass supply curves from separate 
biomass sector models. Thus, integrated assessment models have not commonly been used to analyze the impact of the $2^{\circ} \mathrm{C}$ target on woody biomass use.

There are not many studies that use a global forest sector model to analyze the impact of the $2^{\circ} \mathrm{C}$ target on global woody biomass use. Raunikar et al. (2010) studied the effects of the IPCC SRES scenarios (IPCC 2000) on global woody biomass use using the Global Forest Products Model (Buongiorno et al. 2003). They concluded that moving from the low mitigation scenario (A2) to the high mitigation scenario (A1B) would increase woody biomass use for energy from 5 to $10 \mathrm{Gm}^{3}$ in 2060 leading to threefold higher roundwood prices and a 15\% decrease in woody biomass material use. Favero and Mendelsohn (2017) studied the effects of reaching different radiative forcing levels on global woody biomass use during 2010-2100 using the Global Timber Model (Sohngen et al. 1999) and the WITCH integrated assessment model (Bosetti et al. 2006). They concluded that reaching the $2.5 \mathrm{~W} / \mathrm{m}^{2}$ $\left(2.3^{\circ} \mathrm{C}\right.$ scenario) level would increase woody biomass use for energy from 0 to $5.2 \mathrm{Gm}^{3}$ in 2100 compared to $6.6 \mathrm{~W} / \mathrm{m}^{2}$ level (no mitigation scenario), leading to almost tenfold higher roundwood prices and a $90 \%$ decrease in woody biomass material use.

Some studies have analyzed the implications of higher woody biomass use for energy on woody biomass material use in the more specific context. Johnston and van Kooten (2016) and Jonsson and Rinaldi (2017) studied the interconnection between wood pellets and woody biomass material use by using a global forest sector model. Both studies found that higher wood pellets consumption within the EU28 benefits sawnwood and plywood production while it inhibits fiberboard and pulp productions. However, these studies did not considered the whole woody biomass use for energy, but only a small part of it. Moreover, they did not connect their analysis to any climate scenarios. Consequently, on basis of these studies we cannot draw any general conclusion on the impact of climate change mitigation on the woody biomass use.

The demand for woody biomass depends not only on the climate change mitigation, but also on socioeconomic drivers. The old IPCC SRES scenarios do not separate climate change components from socioeconomic drivers (IPCC 2000), which means that the effects of mitigation cannot be studied independently of the effects of population and GDP growth. In the new SSP-RCP scenario framework, this problem is solved by separating these two components into a matrix of Shared Socioeconomic Pathways (SSPs) and Representative Concentration Pathways (RCPs) (Riahi et al. 2017). The RCPs describe projections for atmospheric concentration of greenhouse gases under different climate change mitigation policies. The SSPs add the socioeconomic dimension to the scenario framework, describing different pathways of population and economic growth and consumption patterns, from sustainable development to highly disintegrated global development and fossil-fuel driven economies.

In this study, we analyze the implications of the SSP-RCP scenarios for woody biomass use using the Global Biosphere Management Model (GLOBIOM) (Havlik et al. 2011, 2014). In particular, we examine the RCPref and RCP2.6 scenarios, which are, respectively, the nomitigation (zero carbon price) and high mitigation $\left(2^{\circ} \mathrm{C}\right.$ target) climate change scenarios. The results of this study are based on solving the GLOBIOM model alone. We do not solve the full GLOBIOM-MESSAGE integrated assessment model (Frico et al. 2017), but instead use the existing results from the SSP-RCP scenarios, which were calculated by the full model. 
The rest of the paper is organized as follows. In Section 2 we introduce the model and the methodology used in the analysis. Section 3 presents the results of the model. In section 4 we discuss the results of the model and provide conclusions. A formal description of the model, numerical results of the model in table format, and a sensitivity analysis are included in the supplementary material.

\section{Methods}

\subsection{GLOBIOM model}

The Global Biosphere Management Model (GLOBIOM) is a global spatially explicit agricultural and forest sector model, in which the world is divided into 30 economic regions and about 200000 land-use units (Havlik et al. 2011, 2014). The model is solved recursively using biophysical data from the spatially explicit forest growth and management model, G4M [Kindermann et al. (2006), Kindermann et al. (2008), Gusti (2010)] and the spatially explicit crop model, EPIC (Williams 1995). In this study, we use a variant of GLOBIOM with an extended description of the forest sector (Lauri et al. 2014). The biomass demands for energy and carbon prices are based on the SSP-RCP scenario calculations from the GLOBIOMMESSAGE integrated assessment framework (Fricko et al. 2017).

The forest sector module in GLOBIOM includes three types of products: primary products, by-products and final products. Primary products come directly from the forests and their supply is based on the production costs and bio-physical data from G4M. Primary products are transformed into final products and by-products using different production technologies. By-products can be used to substitute for primary products in the production of final products. Final products are consumed and their consumption is based on exogenous demand functions. Figure 1 describes the relationships between different products and production technologies in the forest sector module using 2010 model values. The formal description of the forest sector module can be found in the supplementary material.

The current version of the model includes five primary products (pulplogs, sawlogs, other industrial roundwood, fuelwood, and logging residues). Pulplogs, sawlogs, other industrial roundwood and fuelwood are stemwood. Logging residues are branches, stumps, and harvest losses (=stemwood that is not suitable for material use). Other industrial roundwood is stemwood used for material products, but not accounted for pulplogs and sawlog (poles, balks etc.). If there is insufficient stemwood to cover the FAOSTAT fuelwood demand, then branches, stumps and harvest losses are allowed to be used for fuelwood.

The current version of the model includes eight final products (sawnwood, plywood, fiberboard, chemical pulp, mechanical pulp, other industrial roundwood, fuelwood, and energy wood) and five by-products (sawdust, woodchips, bark, black liquor, and recycled wood). Note that other industrial roundwood and fuelwood are primary products as well as final products. Energy wood is an aggregate term for industrial sector woody biomass use for energy. Recycled wood is a by-product of final products (material) consumption. Further 
processing of chemical and mechanical pulp to paper and board and recycled paper are not considered in this version of the model. Note also that woody biomass use for energy is considered in terms of primary energy, which means that further processing of energy wood to liquid biofuels, charcoal and pellets is not considered explicitly in this version of the model.

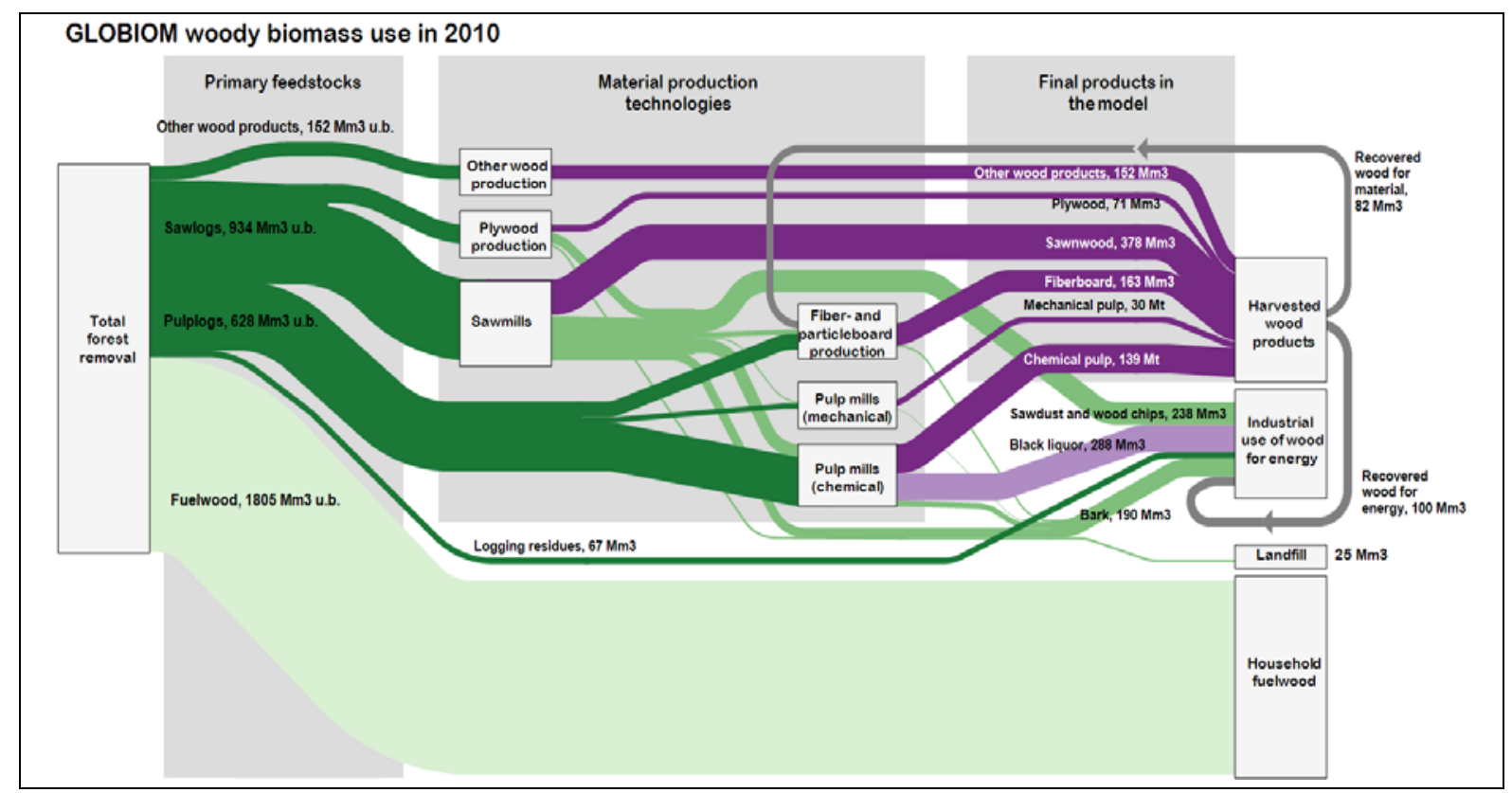

Figure 1: Global woody biomass use in GLOBIOM in 2010.

To simplify the argumentation in the remaining part of the study we use the terms "material use" and "energy use", which are commonly used in the woody biomass resource balance literature (e.g., Mantau et al. 2010). These terms refer to the use of woody biomass as input to production technologies that produce final products for material or energy consumption. For example, sawlogs used for sawnwood production are fully included in material use, even though some part of them end-up as by-products that might be used for energy. On the other hand, primary products and by-products used for pellets and charcoal production are included in energy use, even though pellets and charcoal are, in fact, material products.

\subsection{Linkage between GLOBIOM, G4M and MESSAGE}

The GLOBIOM-MESSAGE integrated assessment model allows a comprehensive accounting of forest, agricultural and energy sector carbon emissions and mitigation options. In terms of forest sector, the framework allows the consideration of mitigation options such as energy substitution, carbon sequestration in forests, afforestation and deforestation. The linkage between GLOBIOM, G4M and MESSAGE is presented in Figure 2. A similar figure for the full integrated assessment model linkages can be found in Fricko et al. (2017).

The linkage between GLOBIOM, G4M and MESSAGE works as follows. First, G4M is solved for a representative forest management called "current management", which keeps the biomass stocks and increments constant over time (Gusti 2010). Current management is independent of harvest volumes and carbon prices, as it assumes that all forests are normal forests where the oldest age class is either harvested or removed by natural mortality or 
natural disturbances. Second, the biomass stocks, increments and forest areas from G4M are used as input to GLOBIOM to calculate the harvest volumes and land prices for given biomass demand and carbon price scenarios. Third, the harvest volumes, carbon prices, and land prices from GLOBIOM are used as input to G4M to solve the actual biomass stocks, increments, and forest areas. The actual biomass stocks, increments and forest areas are not based on the normal forest assumption, but on the actual age-class distribution of forests and the future harvest volumes, carbon prices and land prices. Fourth, the biomass supply curves and land-use based carbon emissions/uptake for different carbon prices from GLOBIOM and G4M are used as input to MESSAGE to calculate the biomass demands for energy and carbon prices required to achieve certain climate scenarios. Finally, the biomass demands for energy and carbon prices for different climate scenarios are used as input to GLOBIOM to solve the final outcome of the model.

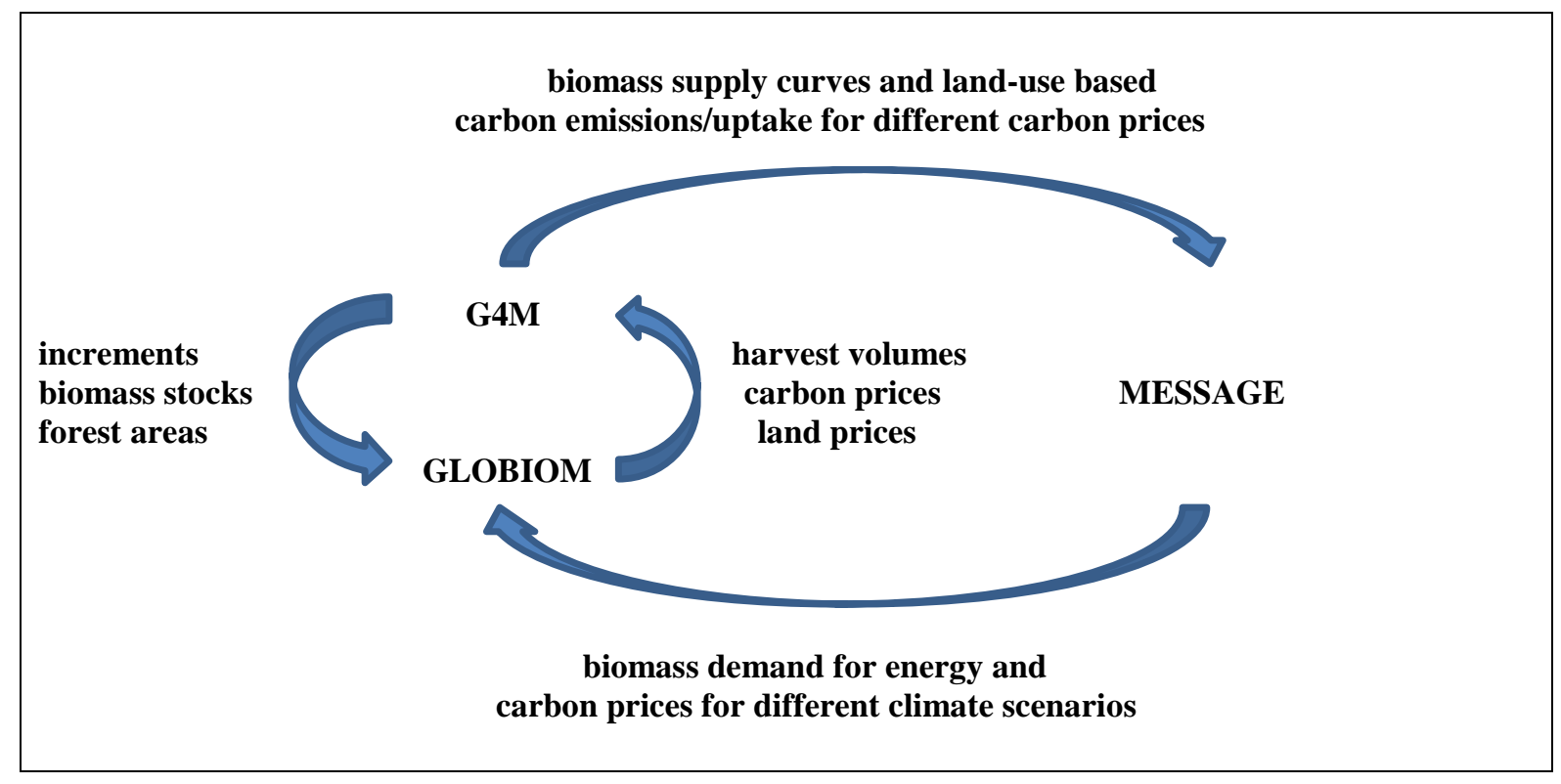

Figure 2: Linkage between GLOBIOM, G4M and MESSAGE.

The results of this study are based on solving the GLOBIOM model alone. We do not solve the full GLOBIOM-MESSAGE integrated assessment model, but instead use the results from the SSP-RCP scenario calculations based on the full model. This means that biomass demand for energy, carbon prices, increments, biomass stocks, and forest areas can be interpreted as exogenous data from the viewpoint of this study. However, the division of biomass use between different types of biomass is endogenous in the sense that is based on the GLOBIOM model outcome.

\subsection{SSP-RCP scenario data}

In this study, we consider two climate change scenarios RCPref and RCP2.6 connected to one socioeconomic development scenario, SSP2. RCPref is the no-mitigation (zero carbon price) scenario leading to a $3.8^{\circ} \mathrm{C}$ temperature increase in 2100 compared to the pre-industrial level. $\mathrm{RCP} 2.6$ is the high mitigation scenario leading to a $1.8^{\circ} \mathrm{C}$ temperature increase in 2100 compared to the pre-industrial level. SSP2 is the "middle of the road" scenario with intermediate socio-economic development (Riahi et al. 2017). 
The carbon prices increase in the RCP2.6 scenario up to $1000 \$ / \mathrm{tCO}_{2}$ in 2100 , while the global biomass demand for energy up to $206 \mathrm{EJ} .{ }^{1}$ Such high carbon prices and biomass demands are not uncommon in the integrated assessment models [e.g., IPCC (2014), Rose et al. (2014), IIASA (2016)]. High carbon prices increase biomass demand for energy, because using fossil fuels becomes less desirable. On the other hand, high carbon prices decrease the biomass demand for energy, because carbon sequestration in forests becomes more desirable, energy efficiency improves and carbon capture and storage (CCS) becomes a more attractive solution. The SSP-RCP scenario calculations take account of these effects and solve the optimal biomass demand for energy, carbon sequestration in forests, forest area changes and carbon prices required to reach the desired climate target (Fricko et al. 2017).

\subsection{Energy sector data interpretation}

The global biomass use for energy in 2010 in terms of primary energy was 54 EJ, of which 34 EJ was residential sector use and 20 EJ industrial sector use (IEA 2016). Energy sector assessments usually assume that the entire residential sector use is fuelwood [e.g., IEA (2009), IPCC (2012), GEA (2012), WBA (2015)]. However, this is more than double the fuelwood consumption in FAO statistics, which was $2.1 \mathrm{Gm}^{3}$ over bark (o.b.) ( $\left.\approx 15 \mathrm{EJ}\right)$ in 2010 (FAO 2016). ${ }^{2}$ The reason for the difference may be that IEA residential sector use also includes non-woody biomass, such as agricultural residues, especially in regions with a large agriculture sector (e.g., India, China, Africa). Suspecting this, we based our fuelwood estimate on FAO rather than IEA data, and assumed that residential sector biomass use (34 EJ) consists of 15 EJ fuelwood and 19 EJ other biomass. Industrial sector biomass use (20 EJ) is estimated to include 8 EJ woody biomass and 12 EJ energy crops and other biomass, based on our own calculations and additional data (IEA 2016, FAO 2016).

\subsection{Fuelwood}

Fuelwood is defined as residential sector (=households) woody biomass use for energy. According to the FAO, fuelwood consumption in 2010 was $2.1 \mathrm{Gm}^{3}$ o.b. $(\approx 15 \mathrm{EJ})$, which was about 28\% of global biomass use for energy (FAO 2016, IEA 2016). The majority of fuelwood consumption (90\%) is located in the developing regions (FAO 2016), where fuelwood is often the most important source of energy. Following the SSP2 storyline we assume that fuelwood consumption is phased out by 2080 (Fricko et al. 2017). Historically, fuelwood consumption has been decreasing in the developed regions and increasing in the developing regions (Fernandes et al.2007). The SSP2 storyline assumes that the developing regions follow the historical path of the developed regions and move from fuelwood to electricity and modern cooking fuels as a result of income growth, urbanization, and active investment policies [Hofstad et al. (2009), Pachauri et al. (2013), Jiang and O’Neill (2017)].

\subsection{Energy crops and other biomass}

Energy crops are defined as biomass that is grown for energy. Energy crops include wood crops (e.g., eucalyptus, poplar, willow), energy grasses (e.g., switchgrass, miscanthus) and agricultural crops (e.g., sugarcane, sugar beet, soy, corn, wheat, rape, oil palm). The energy crops potential is studied, e.g., by Sims et al. (2006), Beringer et al. (2011), Kocar and Civas (2013) and Searle and Malins (2014). Energy crops are expected to become an important

\footnotetext{
${ }^{1}$ Biomass demands for energy and carbon prices as well as other SSP-RCP scenario data are publicly available in the SSP-scenario database (IIASA 2016).

${ }^{2}$ Woody biomass volumes are converted to energy units using factor $1 \mathrm{GJ}=7.2 \mathrm{~m}^{3}$.
} 
source of biomass for energy, because they have higher yields than woody biomass from natural forests. The energy crops yields in the model are on average $25 \mathrm{~m} 3 / \mathrm{ha} / \mathrm{yr}(11 \mathrm{t} / \mathrm{ha} / \mathrm{yr})$ and they vary in the range of $10-45 \mathrm{~m}^{3} / \mathrm{ha} / \mathrm{yr}(5-20 \mathrm{t} / \mathrm{ha} / \mathrm{yr})$, which is comparable to estimates of energy crops yields in other studies (e.g., Searle and Malins 2014). The average increment of natural forests in the model is $6.1 \mathrm{~m}^{3} / \mathrm{ha} / \mathrm{yr}$, which indicates that energy crops plantations require on average four times less land area than natural forests to provide the same amount of biomass for energy use.

Other biomass is defined as residential or industrial sector biomass use for energy that is not included in woody biomass or energy crops. Non-woody biomass can be agricultural residues, waste or biogas. The other biomass potential is studied, e.g., by Bentsen et al. (2014), Searle and Malins (2014) and Daioglou et al. (2015).

There are no good data available about the actual amount of energy crops and other biomass, as IEA data do not differentiate in detail between the different types of biomass for energy (IEA 2016). For that reason, the amount of energy crops and other biomass in 2010 is estimated as a residual term, which explains the difference between the IEA total biomass use for energy and woody biomass use for energy. After 2010 the amount of energy crops and other biomass is modeled endogenously and is based on the economic trade-off between woody biomass, energy crops and other biomass.

\subsection{Harvest potential and cost-supply curves for roundwood and logging residues}

A simple way to summarize the biophysical and economic data that the model uses is to consider harvest potential and cost-supply curves. Harvest potential is usually defined for roundwood (=pulplogs+sawlogs+other industrial roundwood+fuelwood) and extended to logging residues using biomass expansion factors (Verkerk et al. 2011). Cost-supply curves for roundwood and logging residues are obtained by combining harvest potential to production costs.

The global roundwood harvest potential in the model in 2010 is about $19.1 \mathrm{Gm}^{3}$ o.b. $\approx 4.9$ $\mathrm{m}^{3} / \mathrm{ha} / \mathrm{yr} \times 3893 \mathrm{Mha}$, where $4.9 \mathrm{~m}^{3} / \mathrm{ha} / \mathrm{yr}$ is average roundwood yield (=average increment $6.1 \mathrm{~m}^{3} / \mathrm{ha} / \mathrm{yr}$-average harvest losses $1.2 \mathrm{~m}^{3} / \mathrm{ha} / \mathrm{yr}$ ) and $3893 \mathrm{Mha}$ is available forest area for roundwood harvesting in 2010. The global logging residues harvest potential is about 7.2 $\mathrm{Gm} 3 \approx 0.5 \times\left(1.2 \mathrm{~m}^{3} / \mathrm{ha} / \mathrm{yr}+2.5 \mathrm{~m}^{3} / \mathrm{ha} / \mathrm{yr}\right) \times 3893 \mathrm{Mha}$, where 0.5 is recovery ratio, 1.2 $\mathrm{m}^{3} / \mathrm{ha} / \mathrm{yr}$ is average harvest losses, $2.5 \mathrm{~m}^{3} / \mathrm{ha} / \mathrm{yr}$ is average branches and stumps and 3893 Mha is available forest area for logging residues harvesting.

Production costs in the model are based on three costing components: harvest costs, transport costs, and land-use change costs. Harvest and transport costs are spatially explicit, which implies that supply price is an increasing function of harvested volumes, as the easily accessible low cost resources are used first and the remote high cost resources are used last (Di Fulvio et al. 2016). The land-use change costs are an increasing function of the periodic change of the country-level managed forest area, which implies that supply is less elastic in the short run than in the long run, i.e., the harvest potential is higher in the long run than in the short run (Figure 3). This means that in the short run, institutional factors such as the forest ownership structure, available machinery and labor, transport capacity or the forest road network limit the supply; in the long run, such limitations are negligible. 


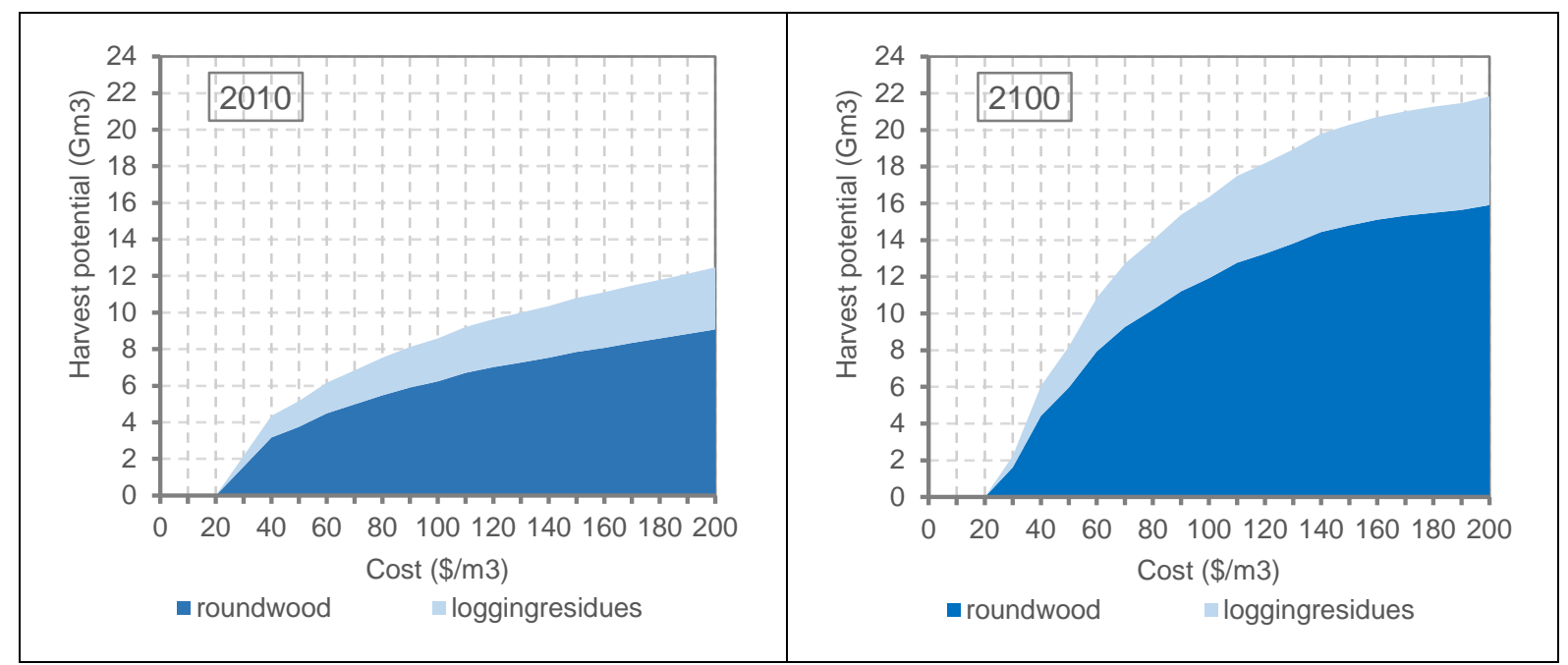

Figure 3: Global cost-supply curves for roundwood and logging residues in 2010 and 2100.

\section{Results}

The results of the model are presented in Figures 4-8, which display the most important numerical and qualitative relationships between the state variables of the model at global and regional level. The numerical results of the model are included in the supplementary material.

The regional level data are aggregated to six regions, which are called EU28, Russia, Africa, Asia, North-America and South-America. The EU28 includes European Union; Russia includes Russia and the rest of Europe; Africa includes Africa and Middle-East; Asia includes Asia and Oceania; North-America includes Canada and the USA; South-America includes Central and South-America. In some cases, the regional level data are aggregated to two regions, which are called boreal zone and tropical zone. Boreal zone includes Russia, North-America and EU28 while tropical zone Africa, Asia and South-America.

\subsection{Total biomass use for energy}

The $2^{\circ} \mathrm{C}$ target increases the total biomass use for energy significantly compared to the nonmitigation scenario (Figure 4). In the RCPref, scenario the total biomass use for energy increases from $54 \mathrm{EJ}$ in 2010 to $66 \mathrm{EJ}$ in 2100, while in the RCP2.6 it increases to $206 \mathrm{EJ}$ in 2100. In the RCPref scenario, the growth of total biomass demand for energy is fully satisfied by energy crops and other biomass, which keeps woody biomass use for energy almost constant over time. In the RCP2.6 scenario, the strong increase in total biomass demand for energy leads to a considerable increase in woody biomass use, as well as development of energy crops and other biomass. 


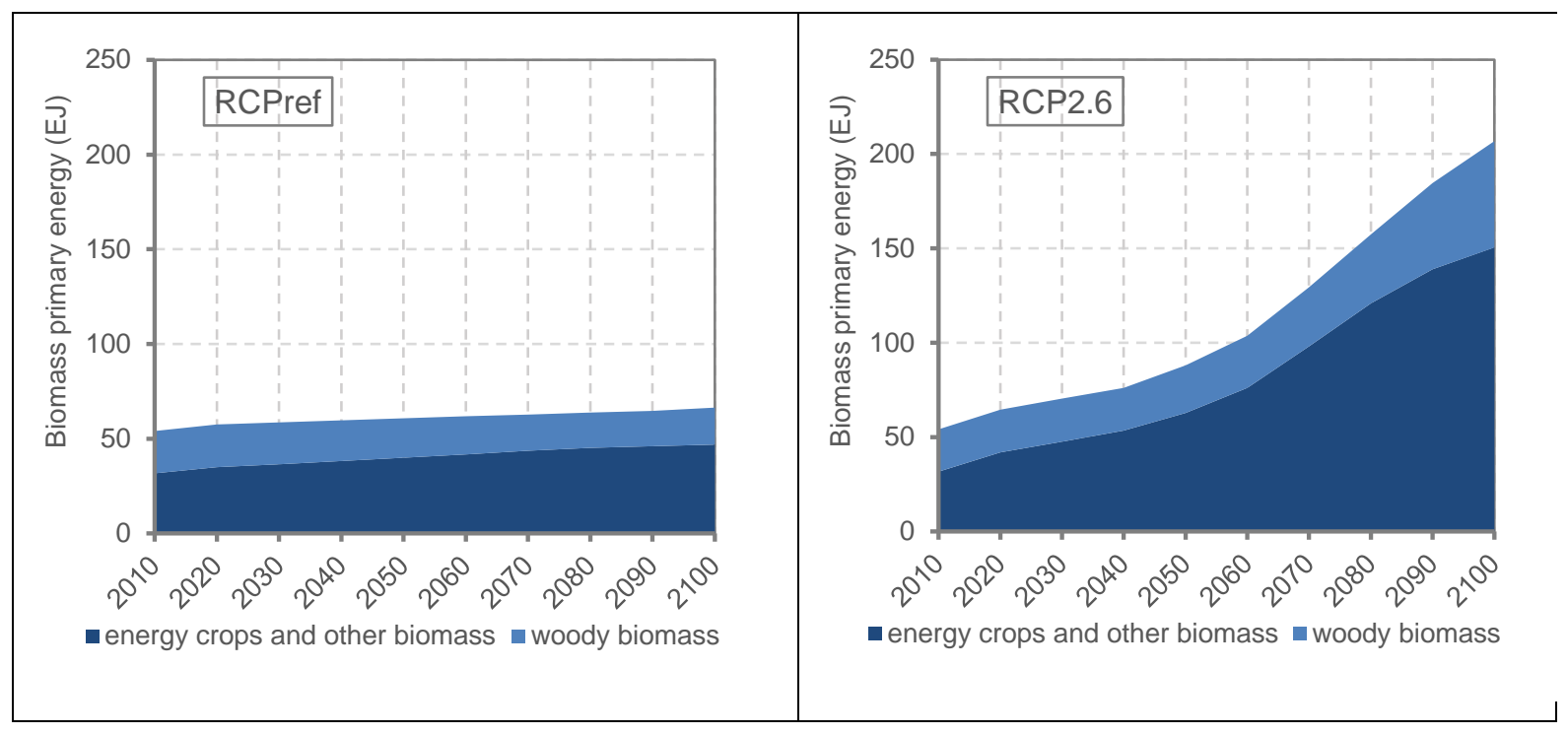

Figure 4: Total global biomass use for energy in the RCPref and RCP2.6 scenarios.

\subsection{Woody biomass energy use}

The higher total biomass use for energy needed to reach the $2^{\circ} \mathrm{C}$ target increases woody biomass use for energy significantly compared to the non-mitigation scenario (Figure 5a). In 2010, most woody biomass use for energy was household fuelwood. While the fuelwood consumption decreases over time, our results indicate a strong increase in woody biomass use for energy in the industrial sector. In the RCPref scenario, the growth of industrial sector use is almost fully satisfied by forest industry by-products, which implies that logging residues use for energy remains at a relatively low level, increasing to $131 \mathrm{Mm}^{3}$ by 2100 , while roundwood is not used for energy at all. In the RCP2.6 scenario, there are insufficient byproducts available to satisfy the increased biomass demand for energy. The logging residues and industrial sector roundwood use for energy thus become important sources of energy especially after 2050 , increasing to $2.6 \mathrm{Gm}^{3}$ and $2.4 \mathrm{Gm}^{3}$ o.b. by 2100 , respectively.

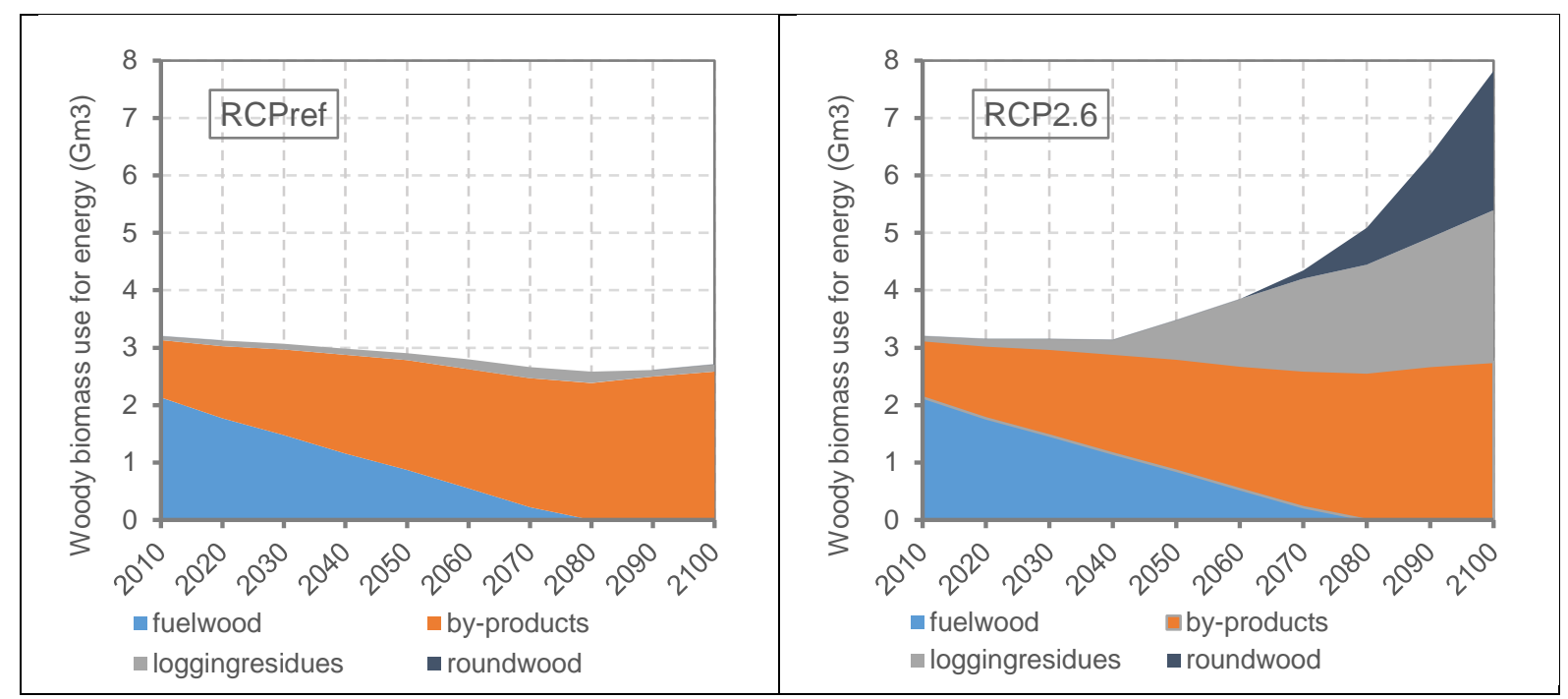

Figure 5a: Woody biomass use for energy in the RCPref and RCP2.6 scenarios. 
At the regional level, woody biomass use for energy increases most in the tropical regions due to the $2^{\circ} \mathrm{C}$ target (Figure $5 \mathrm{~b}$ ). This is because those regions have larger forest resources and lower production costs as well as faster socioeconomic development than the rest of the world. In the RCPref scenario woody biomass use for energy in the tropical regions decreases from $2.4 \mathrm{Gm}^{3}$ in 2010 to $1.9 \mathrm{Gm}^{3}$ in 2100 due to phasing out of fuelwood consumption.

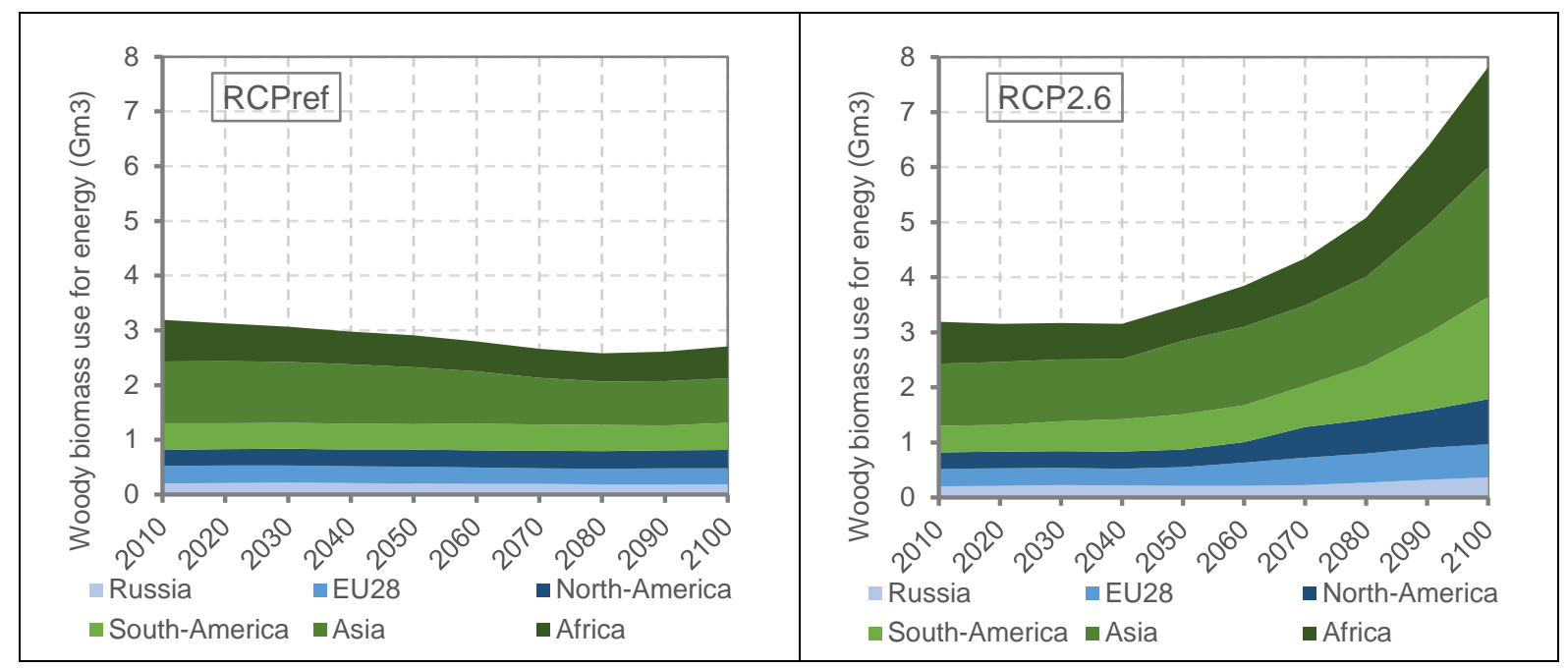

Figure 5b: Regional division of woody biomass use for energy in the RCPref and RCP2.6 scenarios.

Also noteworthy is the different regional composition of woody biomass use for energy (Figure 5c). In the boreal zone, forest industry by-products cover the majority of woody biomass use for energy, which keeps roundwood use for energy low (about 10\% of total woody biomass use for energy in the RCP2.6 scenario in 2100). In the tropical zone, the lower availability of forest industry by-products and the higher availability of roundwood lead to higher roundwood use for energy (about $40 \%$ of total woody biomass use for energy in the RCP2.6 scenario in 2100). Altogether, $90 \%$ of roundwood use for energy in the RCP2.6 scenario in 2100 (2.2 $\mathrm{Gm}^{3}$ o.b.) is located in the tropical zone, while only $10 \%(0.2$ $\mathrm{Gm}^{3}$ o.b.) is in the boreal zone.

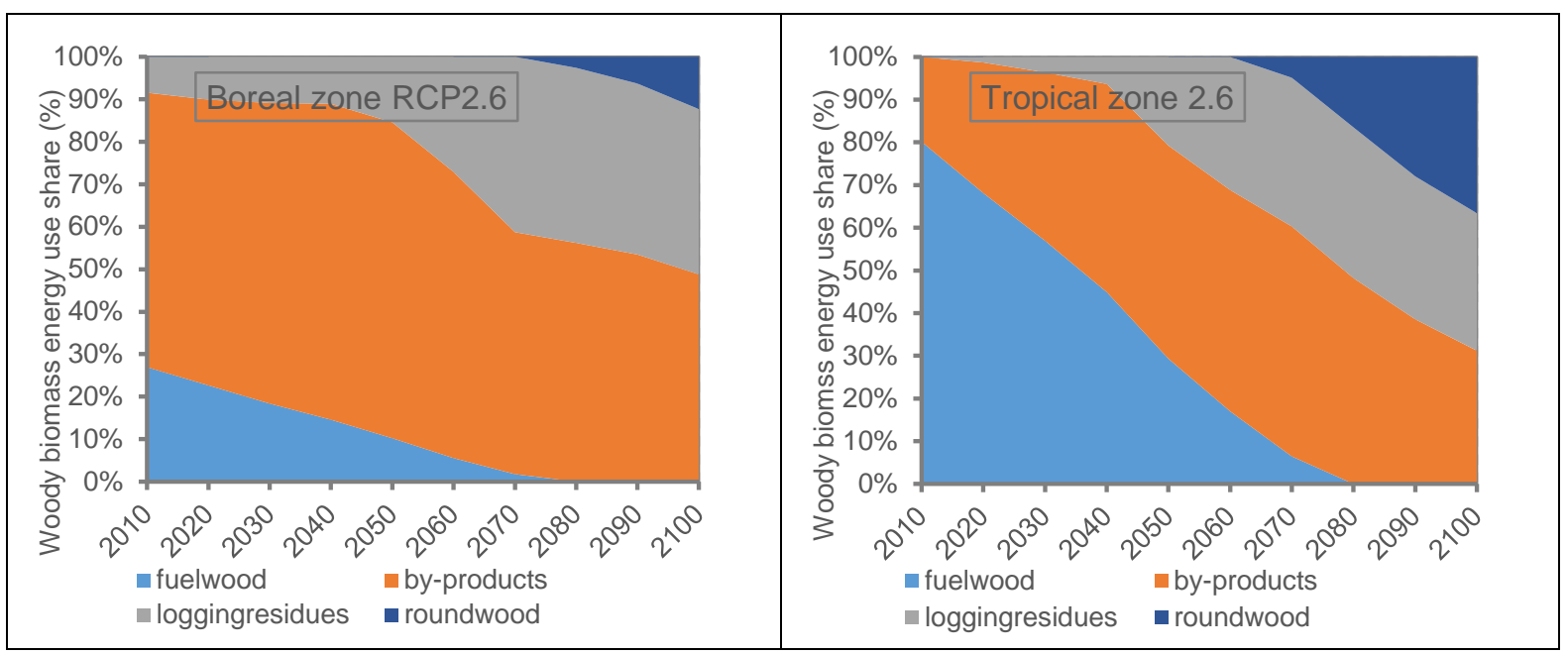

Figure 5c: Composition of woody biomass use for energy in the boreal zone and in the tropical zone in the RCP2.6 scenario. 


\subsection{Woody biomass material use}

The higher woody biomass use for energy needed to reach the $2^{\circ} \mathrm{C}$ target increases the competition over woody biomass resources, which tends to decrease woody biomass material use (=competition effect). On the other hand, higher woody biomass use for energy increases forest industry by-products demand for energy, which makes forest industry final products production more profitable and tends to increase woody biomass material use (=by-product effect). The overall effect of the higher woody biomass use for energy on woody biomass material use depends on the trade-off between these two effects. In general, the overall effect tends to be an inverted u-shaped function of time, because the competition effect becomes stronger over time when woody biomass use for energy increases.

The higher biomass use for energy needed to reach the $2^{\circ} \mathrm{C}$ target increases woody biomass material use slightly compared to the non-mitigation scenario (Figure 6a). The effect is an inverted u-shaped function of time so that the peak $130 \mathrm{Mm}^{3}$ occurs in 2080 after which it decreases to $42 \mathrm{Mm}^{3}$ in 2100 . This is because by-products cover the majority of industrial woody biomass use for energy until 2080 (Figure 5a). After 2080 roundwood use for energy starts to increase reaching about $30 \%$ share of total woody biomass energy use in 2100 , which tends to increase the competition effect.

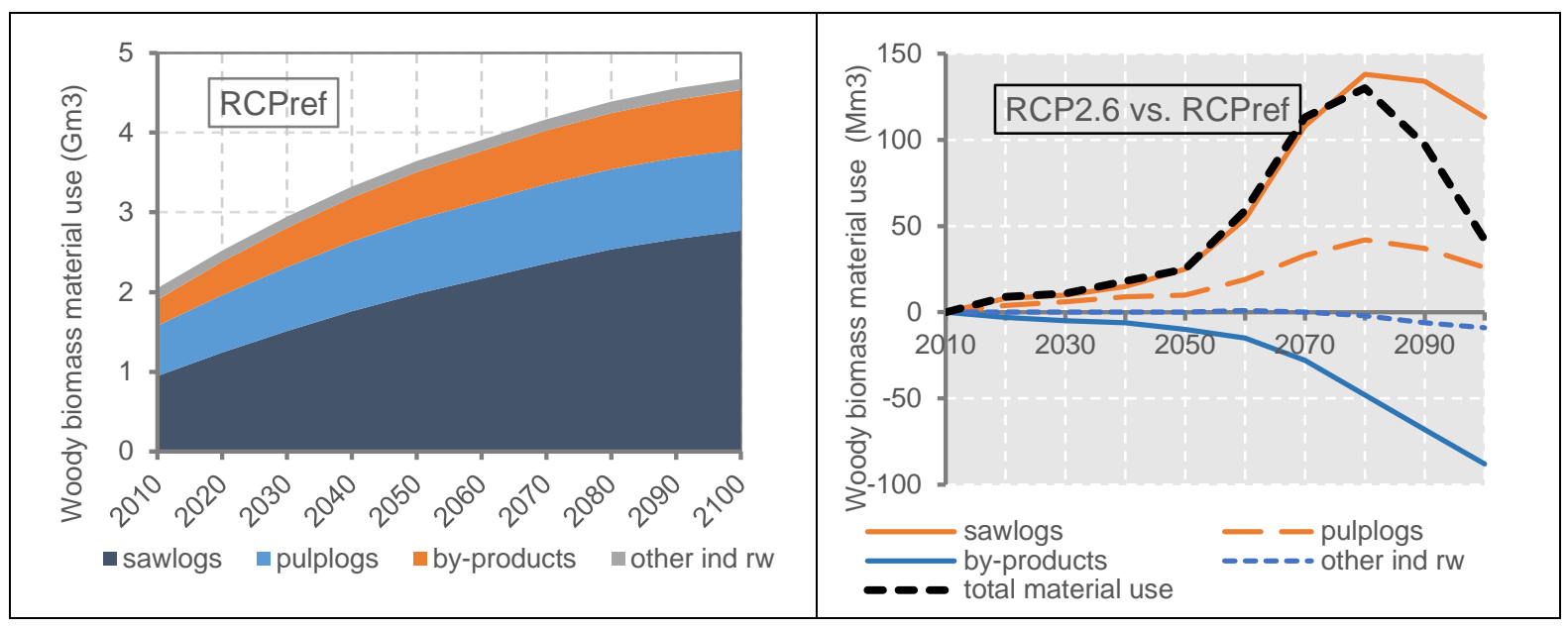

Figure 6a: Woody biomass material use. The left hand chart display development in the RCPref scenario using $\mathrm{Gm}^{3}$ while the right hand chart the difference between RCP2.6 and RCPref scenarios using $\mathrm{Mm}^{3}$.

The higher woody biomass use for energy needed to reach the $2^{\circ} \mathrm{C}$ target increases woody biomass use for sawnwood, plywood and chemical pulp and decreases its use for mechanical pulp, fiberboard and other industrial roundwood (Figure 6b). Sawnwood, plywood, and chemical pulp production increase, because they provide large amounts of by-products (woodchips, sawdust, bark, black liquor). Fiberboard, mechanical pulp and other industrial roundwood productions decrease, because they provide small amounts of by-products (only bark). 


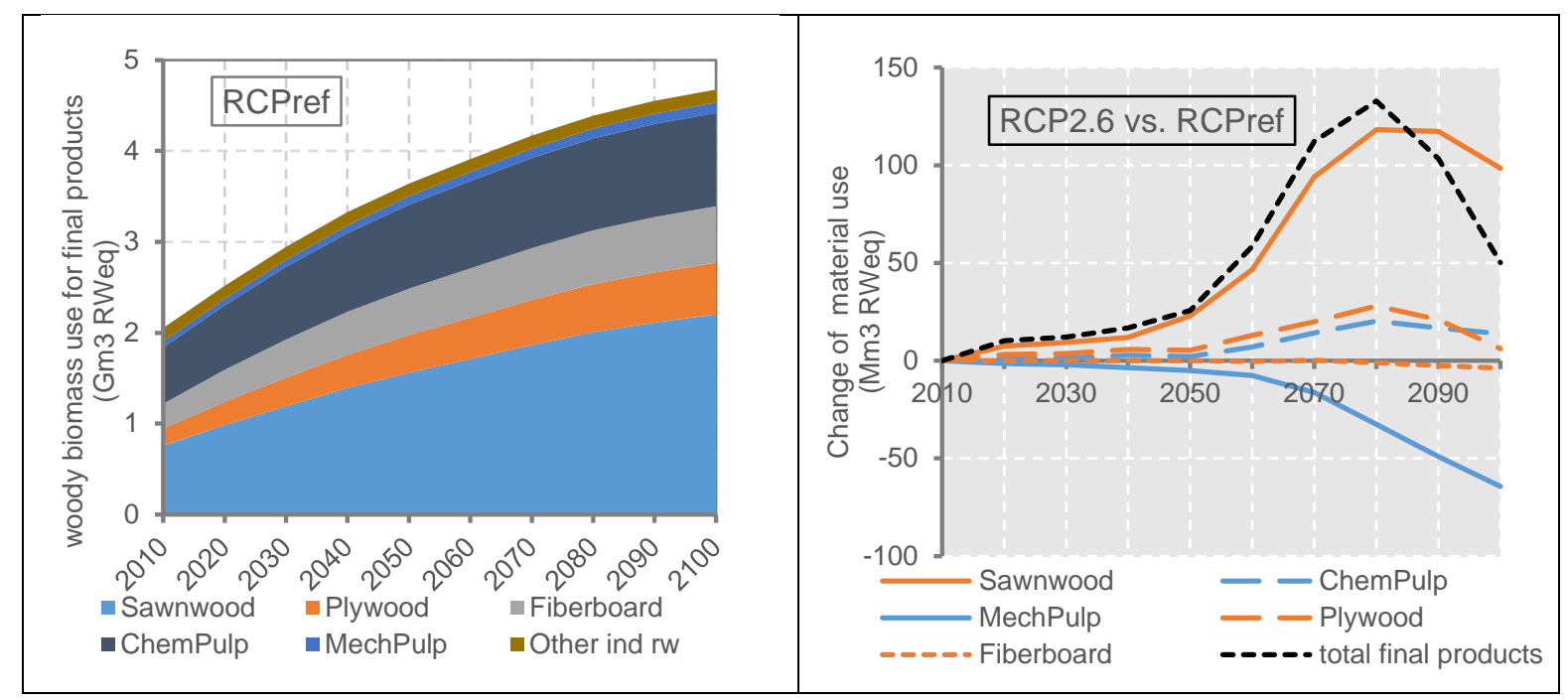

Figure 6b: Woody biomass material use measured in terms of final products. The left hand chart display development in the RCPref scenario using $\mathrm{Gm}^{3} \mathrm{RWeq}$ while the right hand chart the difference between RCP2.6 and RCPref scenarios using $\mathrm{Mm}^{3}$ RWeq. ${ }^{3}$

The higher biomass use for energy needed to reach the $2^{\circ} \mathrm{C}$ target increases woody biomass material use in Russia, North-America and EU28 and decreases it in Africa, Asia and, SouthAmerica (Figure 6c). In general, woody biomass use for energy needed to reach the $2^{\circ} \mathrm{C}$ target has a positive effect on boreal zone material use and a negative effect on tropical zone material use. This is because by-products are used relatively more for energy in the boreal zone (Figure 5c), which increases the by-product effect there, while the roundwood is used relatively more for energy in the tropical zone, which increases the competition effect there.

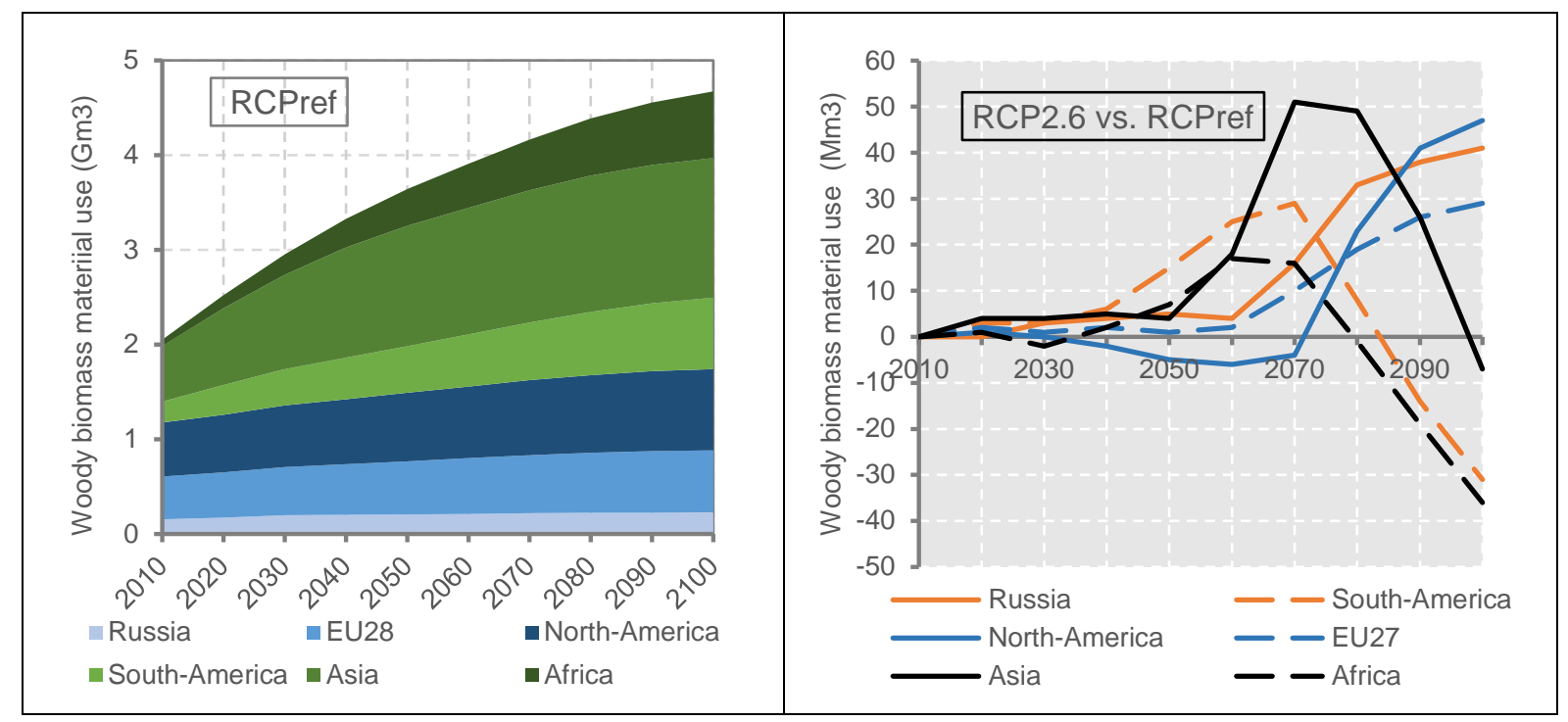

Figure 6c Regional division of woody biomass material use. The left hand chart displays development in the RCPref scenario using $\mathrm{Gm}^{3}$ while the right hand chart the difference between RCP2.6 and RCPref scenarios using $\mathrm{Mm}^{3}$.

\footnotetext{
${ }^{3}$ In Figure 6b we use the roundwood equivalent units (RWeq) to final products comparable to each other. This means that final products are measured in terms of their raw material consumption instead of their actual volume.
} 
The turning point of material use expansion occurs at the global level in around 2080 (Figure $6 a)$ while in the tropical zone it occurs in around 2070. In the boreal zone the turning point is outside of the considered time horizon (Figure 6c). Figure 4 shows that the turning point occurs when roundwood use for energy exceeds $10 \%$ of total woody biomass use for energy. Accordingly, we can conclude that an inverted u-shaped effect requires roundwood use for energy to exceed $10 \%$ share of total woody biomass use for energy. If roundwood use for energy stays sufficiently low (below $10 \%$ of total woody biomass use for energy) then the byproduct effect tends to dominate the competition effect and we do not observe the inverted ushaped effect.

\subsection{Woody biomass prices}

The higher biomass use for energy needed to reach the $2^{\circ} \mathrm{C}$ target increases woody biomass prices significantly compared to the non-mitigation scenario (Figure 7). In the RCP2.6 scenario, pulplogs and sawlogs prices start to increase in 2080 while in the RCPref scenario they starts to decrease. The reason for the increase is the competition effect and higher biomass use for energy while the reason for the decrease is the decreasing trend of material use expansion, which decreases the land-use change costs and leads to lower pulplog and sawlog prices. In the RCP2.6 scenario, the price of by-products and logging residues starts to increase in 2060. This is because the by-product and logging residue prices react to higher biomass use for energy earlier than the roundwood prices.

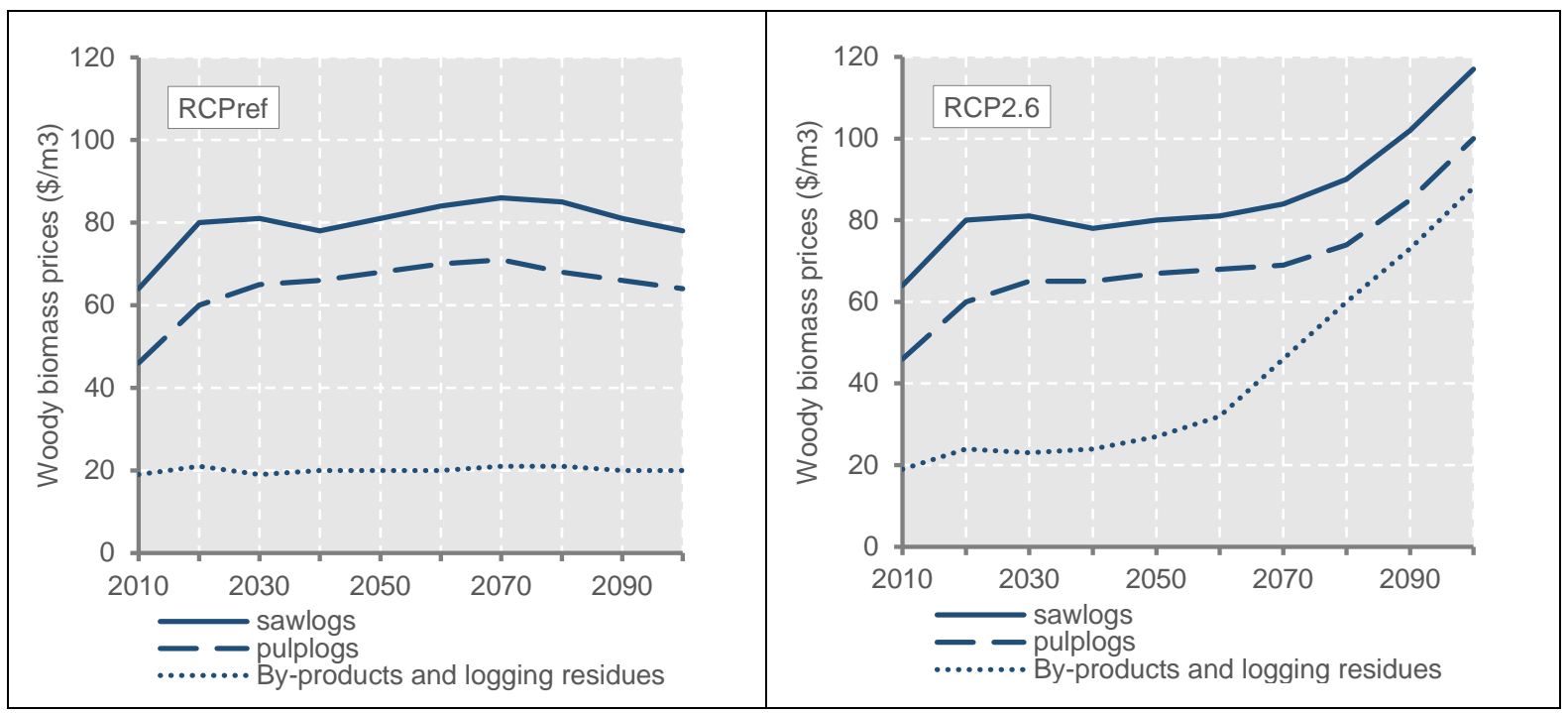

Figure 7: World woody biomass prices calculated as a weighted average over regional prices in the RCPref and RCP2.6 scenarios.

\subsection{Roundwood harvest volumes and the intensity of use of forest resources}

The higher biomass use for energy needed to reach the $2^{\circ} \mathrm{C}$ target increases the roundwood harvest volumes significatly compared to the non-mitigation scenario (Figure 8a). The main reason for this is increased roundwood use for energy in the RCP2.6 scenario. In 2100, the harvest volume in the RCP2.6 scenario is $2.5 \mathrm{Gm}^{3}$ o.b. higher than in the RCPref scenario, of which $2.4 \mathrm{Gm}^{3}$ o.b. is caused by increased roundwood use for energy and $0.1 \mathrm{Gm}^{3}$ o.b. by increased roundwood material use. 


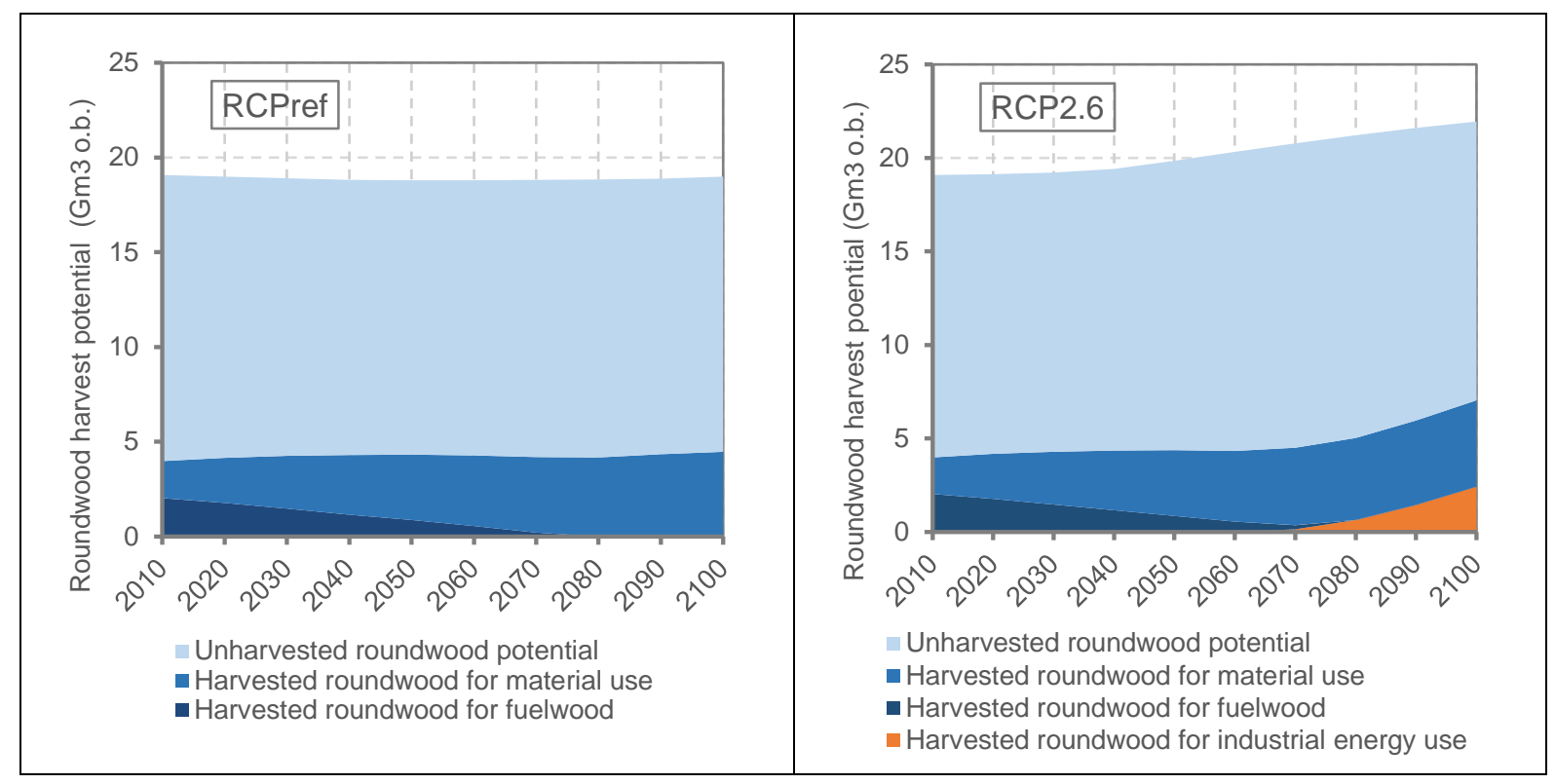

Figure 8a: Roundwood harvest volumes and harvest potential in the RCPref and RCP2.6 scenarios.

The development of harvest volumes over time depends on roundwood material use as well as on roundwood use for energy. In the RCPref scenario, roundwood material use increases from $1.9 \mathrm{Gm}^{3}$ o.b. in 2010 to $4.5 \mathrm{Gm}^{3}$ o.b. in 2100 and energy use decreases from $2.1 \mathrm{Gm}^{3}$ o.b. in 2010 to 0 in 2100, leading to an overall increase in roundwood harvest volumes from $4.0 \mathrm{Gm}^{3}$ o.b. in 2010 to $4.5 \mathrm{Gm}^{3}$ o.b. in 2100 . Thus, the increase in roundwood material use is compensated for by the decrease in fuelwood use, and the overall increase in harvest volumes remains small.

In the RCP2.6 scenario, roundwood material use increases from $1.9 \mathrm{Gm}^{3}$ o.b. in 2010 to 4.6 Gm3 o.b. in 2100 and energy use decreases first from $2.1 \mathrm{Gm}^{3}$ o.b. in 2010 to $0.4 \mathrm{Gm}^{3}$ o.b. in 2070 and then increases to $2.4 \mathrm{Gm}^{3}$ o.b. in 2100, leading to an overall increase in harvest volumes from $4.0 \mathrm{Gm}^{3}$ o.b. in 2010 to $7.0 \mathrm{Gm}^{3}$ o.b. in 2100 . Thus, the increase in roundwood material use is compensated for by the decrease in fuelwood use, but harvest volumes increase due to industrial sector roundwood use for energy.

If we compare the projected harvest volumes to the roundwood harvest potential, the increase seems less dramatic as significant amounts of forest resources will remain unused. One way to describe this relationship is to consider the intensity of use of forest resources, which can be measured by the ratio of roundwood harvest volume to roundwood harvest potential (OECD, 2015). In 2010 the intensity of use of forest resources was about $21 \% \approx 100 \mathrm{x}$ 4.0/19.1, where $4.0 \mathrm{Gm}^{3}$ o.b. is the global roundwood harvest volume in 2010 and $19.1 \mathrm{Gm}^{3}$ o.b. is the global roundwood harvest potential. In the RCPref scenario, the intensity increases to $24 \%$ and in the RCP2.6 scenario to $32 \%$ by 2100 . Note that the roundwood harvest potential stays almost constant in the RCPref scenario while in the RCP2.6 scenario it increases by $15 \%$ during 2010-2100. This is because forest area increase in the RCP2.6 scenario from 3893 Mha in 2010 to 4479 Mha in 2100. Forest area increases in the RCP2.6 scenario due to higher carbon prices, which increase the value of forest land relative to other land use options and lead to lower levels of deforestation and higher levels of afforestation than in the RCPref scenario. 
At the regional level, the $2^{\circ} \mathrm{C}$ target increases harvest volumes the most in the tropical regions (Figure 8b), because $90 \%$ of roundwood use for energy occurs there. Therefore, the $2{ }^{\circ} \mathrm{C}$ target is expected to have largest effect on the tropical zone forest resources use. However, the

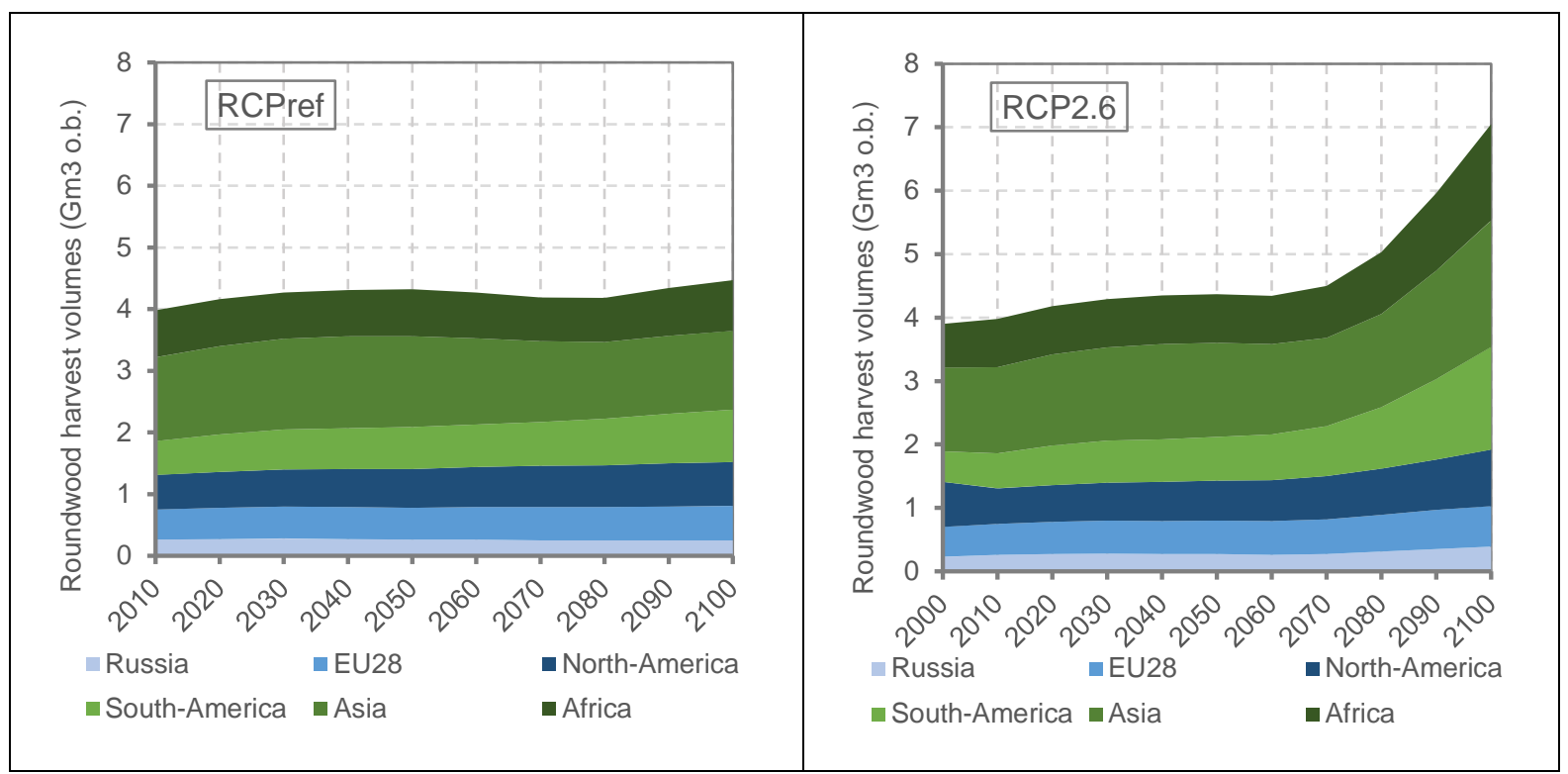

Figure 8b: Regional division of roundwood harvest volumes in the RCPref and RCP2.6 scenarios.

intensity of use of forest resources increases the most in the EU28, where 95\% of forest resources are in production use, in the RCP2.6 scenario in 2100 (Figure 8c). In the tropical regions, the intensity of use of forest resources increases only modestly so that in SouthAmerica 23\%, in Africa 28\%, and in Asia 48\% of forest resources are in production use in the RCP2.6 scenario in 2100. Thus, even if harvest volumes increase significantly in the tropical regions, most of the forest resources remain still unused in those regions.

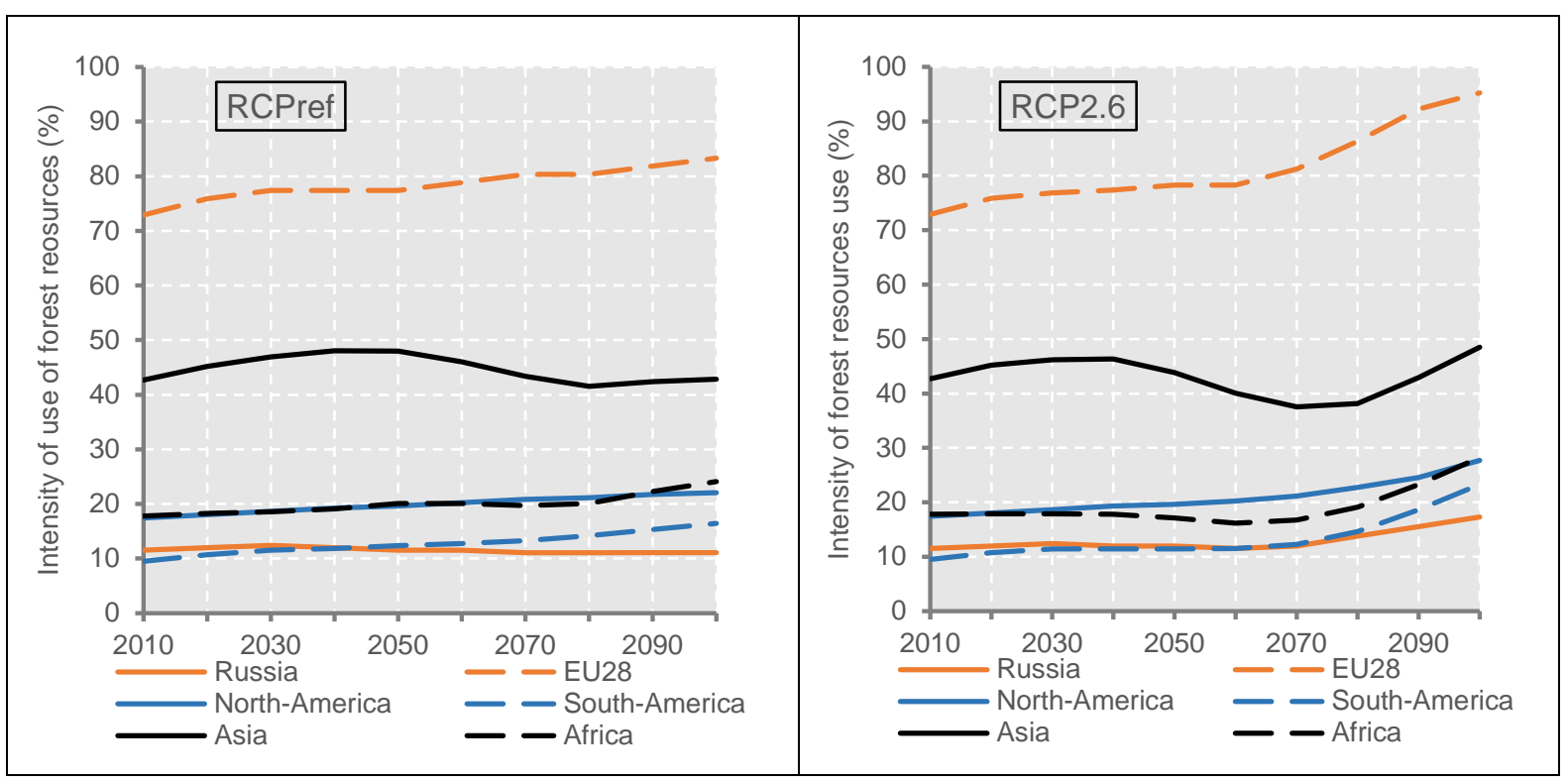

Figure 8c: The intensity of use of forest resources for different regions in the RCPref and RCP2.6 scenarios. 


\section{Discussion and conclusions}

We have shown that the impact of the $2^{\circ} \mathrm{C}$ target on woody biomass material use is not trivial, because the higher woody biomass use for energy needed to reach the $2^{\circ} \mathrm{C}$ target causes an inverted u-shaped effect on woody biomass material use depending on the trade-off between the by-product and competition effects. Our results suggest that the $2{ }^{\circ} \mathrm{C}$ target can be achieved without significant distortions to woody biomass material use and can even benefit some forest industries and regions. Even if the $2^{\circ} \mathrm{C}$ target increases harvest volumes in the tropical regions significantly compared to the non-mitigation scenario, the intensity of use of forest resources in these regions is expected to remain at a relative low level.

The impact of the $2{ }^{\circ} \mathrm{C}$ target on woody biomass material use and prices is smaller than in previous studies on the subject (Table 1), as we have included forest industry by-products and logging residues in our analysis. The forest industry by-products and logging residues increase the availability of woody biomass and make material production more profitable, which tends to decrease competition over woody biomass resources and lower woody biomass prices.

Table 1

Comparison of model assumptions and results with previous studies: ${ }^{\text {a }}$

\begin{tabular}{|c|c|c|c|}
\hline & GLOBIOM & GFPM & GTM \\
\hline Available forest area 2010 (Mha) & 3893 & 3900 & 3500 \\
\hline Available forest area 2100 (Mha) & $3877-4479$ & 3900 & $3200-5000$ \\
\hline Average roundwood yield (m3/ha/y) & 4.9 & $4^{\mathrm{d}}$ & $2^{d}$ \\
\hline Roundwood harvest potential (Gm3 o.b.) & $19.1-22.0$ & $15.6^{\mathrm{d}}$ & $7.0-10.0^{d}$ \\
\hline Roundwood production costs ${ }^{\mathrm{b}}(\$ / \mathrm{m} 3)$ & $20-100$ & - & - \\
\hline Price elasticity of supply & - & $0.1-1$ & $0.3-1.1$ \\
\hline Woody biomass energy use 2010 (Gm3) & 3.2 & 1.9 & $0^{\mathrm{c}}$ \\
\hline Woody biomass energy use 2100 (Gm3) & 2.7-7.8 & 4.9-9.9 & $0-5.2$ \\
\hline Woody biomass material use 2010 (Gm3) & 2.1 & 1.7 & 2.0 \\
\hline Woody biomass material use 2100 (Gm3) & 4.7 & $1.3-1.2$ & $2.6-0.2$ \\
\hline Roundwood harvest volume 2010 (Gm3 o.b.) & 4.0 & $3.6^{\mathrm{d}}$ & $2.0^{d}$ \\
\hline Roundwood harvest volume 2100 (Gm3 o.b.) & $4.5-7.0$ & $6.2-11.1^{\mathrm{d}}$ & $2.6-5.4^{\mathrm{d}}$ \\
\hline Roundwood prices 2010 (\$/m3) & 60 & 70 & 100 \\
\hline Roundwood prices 2100 (\$/m3) & $80-120$ & $150-400$ & $100-1830$ \\
\hline
\end{tabular}

\footnotetext{
${ }^{\mathrm{a}}$ The range of results represents the difference between the low and high mitigation scenarios. GLOBIOM=model used in this study [low mitigation scenario=RCPref, high mitigation scenario=RCP2.6] GFPM=model in Raunikar et al. (2010) [low mitigation scenario=A2, high mitigation scenario=A1B; increments and elasticities from Buongirno et al. (2003); woody biomass material use from Buongiorno et al. (2012); due to different time horizon 2006 represents 2010 and 2060 represents 2100]. GTM=model in Favero and Mendelsohn (2017) [low mitigation scenario=radiative forcing $6.6 \mathrm{~W} / \mathrm{m}^{2}$; high mitigation scenario=radiative forcing $3.4 \mathrm{~W} / \mathrm{m}^{2}$; increments and elasticites from Sohngen et al. (1999); price elasticity of management interpreted as price elasticity of supply].

${ }^{b}$ Roundwood production costs are long run costs, i.e., they include harvest and transport costs, but not land-use change costs.

${ }^{\mathrm{C}}$ Woody biomass energy use in GTM is zero in 2010, because the model does not consider fuelwood, byproducts or logging residues use for energy.

${ }^{\mathrm{d}}$ Under bark.
}

The results of this study depend not only on the availability of woody biomass, but also on other model assumptions. First, the price elasticities of demand are assumed to be relatively inelastic based on Boungiorno et al. (2003. The final products demand might become more 
elastic in the future, because woody biomass can potentially replace other materials, such as concrete, plastic or cotton (Menon and Rao 2012, Mallo and Espinoza 2014). More elastic demand increases the by-product effect, as it facilitates material production expansion.

Second, we do not assume any limitations on roundwood use for energy. For example, in the EU there is an ongoing discussion concerning restrictions on roundwood use for energy to promote the cascading use of wood (Vis et al. 2016). Restricting roundwood use for energy increases the by-product effect, because by-products demand for energy increases. Third, there are several uncertainties connected with large scale production of energy crops and it is unclear if energy crops can achieve their expected potential (Evans 1997, Searle and Malins 2014). Lower availability of energy crops increases the competition effect, as it leads to higher woody biomass use for energy. ${ }^{4}$

In this study, woody biomass use for energy is assumed to be carbon neutral in the sense that the temporary asymmetry between carbon emissions of burning biomass and carbon uptake by regrowth is ignored. Consequently, woody biomass use for energy only affects the carbon balance of forests through the rotation length and permanent carbon stock changes.

Moreover, the harvest potential of the model is determined by forest growth estimates from G4M, which are based on the static Net Primary Productivity (NPP) map (Kindermann et al. 2008). It is thus possible that we overestimate the climate benefits of woody biomass use for energy and underestimate the climate benefits of carbon sequestration in forests. There is ongoing scientific debate regarding how to manage forests to maximize mitigation effort [e.g., Lippke et al. (2011), Schulze et al. (2012), Sedjo and Tian (2012), Agostini et al. (2014), Bellassen and Luyssaert (2014), Johnston and van Kooten (2015), Berndes et al. (2016)]. While our model offers a good starting point for analyzing the impact of climate change mitigation on woody biomass use at the global level, considering possible changes in the forest growth and biomass decomposition processes provides an important subject for future research. One possible solution would be to couple G4M with a process based forest growth model and a soil carbon model, which take account changes in NPP and heterotrophic respiration (Kindermann et al. 2013, Zhou et al. 2013, Cherubini et al. 2016).

Another subject for future study would be to analyze the impact of climate change mitigation jointly with the impact of climate change on forest growth and mortality. The combined effect of climate change and climate change mitigation on woody biomass use has been studied, e.g., by Perez Garcia et al. (2002), Sohngen and Tian (2016) and Tian et al. (2016). Higher temperatures and $\mathrm{CO}_{2}$ concentration not only increase harvest potential, but they also increases the risk for natural disturbances such as storms, pests, and droughts. However, the impact of climate change on forest growth and mortality is not yet completely understood and includes large uncertainties (e.g., Lindner et al. 2014, Sleen et al. 2015). Moreover, in the $2^{\circ} \mathrm{C}$ target scenario the temperature and $\mathrm{CO}_{2}$ concentration changes are expected to be lower than in the non-mitigation scenario, which would decrease the climate effect on forest growth and mortality considerably compared to the non-mitigation scenario with almost $4{ }^{\circ} \mathrm{C}$ temperature increase.

\section{Acknowledgments}

This study was financially supported by Future Forests. Future Forests is a multidisciplinary research program supported by the Foundation for Strategic Environmental Research

\footnotetext{
${ }^{4}$ The supplementary material includes a sensitivity analysis, which considers the effects of higher price elasticities of demand, restrictions on roundwood use for energy, and lower availability of energy crops.
} 
(MISTRA), the Swedish Forestry Industry, the Swedish University of Agricultural Sciences (SLU), Umea University, and the Forestry Research Institute of Sweden (Skogforsk).

Support for this study has also been received from the CRESENDO project (Coordinated Reseach in Earth Systems and Climate: Experiments, Knowledge, Dissemination and Outreach, Grant 641816), as well as the CD-LINKS project (Linking Climate and Development Policies- Leveraging International Networks and Knowledge Sharing, Grant 642147).

\section{References}

Agostini, A., Giuntoli, J. and Boulamanti, A., 2014, Carbon accounting of forest bioenergy, JRC Scientific and Policy Reports 25354, Joint Research Centre of the European Commission.

Bellassen, V. and S. Luyssaert, 2014, Managing forests in uncertain times, Nature 506, 153155.

Bentsen, N., Felby, C. and B. Thorsen, 2014, Agricultural residue production and potentials for energy and material services, Energy and Combustion Science 40, 59-73.

Beringer, T., Lucht, W. and S. Schaphoff, 2011, Bioenergy production potential of global biomass plantations under environmental and agricultural constraints, Global Change Biology Bioenergy 3, 299-312.

Berndes, G., Abt, B., Asikainen, A., et al., 2016, Forest biomass, carbon neutrality and climate change mitigation, From Science to Policy 3. European Forest Institute.

Bosetti, V., Carraro, C., Galeotti, M., et al., 2006, A World Induced Technical Change Hybrid Model. The Energy Journal , 27, 13-38.

Buongiorno, J., Zhu, S., Zhang, D., Turner, J. and D. Tomberlin, 2003, The Global Forest Products Model, Elsevier.

Buongiorno, J., Zhu, S., Raunikar, R., et al., 2012, Outlook to 2060 for World Forests and Forest Industries, A technical Document Supporting the Forest Service 2010 RPA Assessment.

Cherubini, F., Huijbregts, M., Kindermann, G., 2016, Global spatially explicit $\mathrm{CO}_{2}$ emission metrics for forest bioenergy, Scientific Reports 6:20186.

Daioglou, V., Stehfest, E., Wicke, B., et al., 2015, Projections of the availability and cost of residues from agriculture and forestry, GCB Bioenergy 2015.

Di Fulvio, F., Forsell, N., Lindroos, O., et al., 2016, Spatially explicit assessment of roundwood and logging residues availability and costs for the EU28, Scandinavian Journal of Forest Research 31, 691-707.

Evans, J., 1997, Bioenergy plantations-experience and prospects, Biomass and Bioenergy 13, 189-191. 
FAO, 2016, FAOSTAT database. Available at: https://www.fao.org/faostat.

Favero, A. and R. Mendelsohn, 2017, The land-use consequences of woody biomass with more stringent climate mitigation scenarios, Journal of Environmental Protection 8, 61-73.

Fernandes, S., Trautmann, N., Streets, D, et al., 2007, Global biofuel use 1850-2000, Global Biogeochemical Cycles 21, 1-15.

FRA, 2015, Global Forest Resources Assessment, Main Report, FAO.

Fricko, O., Havlik, P., Rogelj, J., et al., 2017, The marker quantification of the Shared Socioeconomic Pathway 2: A middle of the road scenario for the $21^{\text {st }}$ century, Global Enviromental Change 42, 251-267.

Gaulier, G. and S. Zignago, 2010, BACI: International trade database at the product level, CEPII working paper 2010-23.

GEA, 2012, Global Energy Assessment-Toward a Sustainable Future, Cambridge University Press.

Gusti, M., 2010, An algorithm for simulation of forest management decision in the global forest model, Shtuchniy Intelekt (Artificial Intelligence) N4, 45-49.

Havlik, P., Schneider, U., Schmid, E., et al., 2011, Global land-use implications of first and second generation biofuels targets, Energy Policy 39, 5690-5702.

Havlik, P., Valin, H., Herrero, M., et al., 2014, Climate change mitigation through livestock system transition, Proceedings of the National Academy of Science, 111, 3709-3714.

Hofstad, O., Kohlin, G. and J. Namaalwa, 2009, How can emissions from woodfuel be reduced? In: Angelsen, A., Brockhaus, M., Kanninen, M.,et al., Realising REDD+: National strategy and policy options, 237-248.

IEA, 2009, Bioenergy-a sustainable and reliable energy source, Main report, IEA bioenergy 2009:06.

IEA, 2016, IEA energy balance database. Available at: https://tntcat.iea.org/Sankey.

IIASA, 2016, SSP Database, version 1.1. Available at: https://tntcat.iiasa.ac.at/SspDb.

IPCC, 2000, Emissions Scenarios, Special Report of the Intergovernmental Panel on Climate Change.

IPCC, 2012, Bioenergy, chapter 2 in Renewable Energy Sources and Climate Change Mitigation, Special Report of the Intergovernmental Panel on Climate Change.

IPCC, 2014, Assessing Transformation Pathways, in Climate Change 2014: Mitigation of Climate Change. Contribution of Working Group III to the Fifth Assessment Report of the Intergovernmental Panel on Climate. 
Jiang, L and B. O’Neill, 2017, Global urbanization projections for the Shared Socioeconomic Pathways, Global Environmental Change 42, 2017.

Johnston, C. and C. van Kooten, 2015, Back to the past: Burning wood to save the globe, Ecological Economics 120, 185-193.

Johnston, C. and C. van Kooten, 2016, Global trade impacts of increasing Europe's bioenergy demand, Journal of Forest Economics 23, 27-44.

Jonsson, R. and F. Rinaldi, 2017, The impact on global wood-product markets of increasing consumption of wood pellets within the European Union, Energy 133, 864-878.

Kindermann, G., Obersteiner, M., Rametsteiner, E. and I. McCallum, 2006, Predicting the deforestation-trend under different carbon-prices, Carbon Balance and Management 1, 1-17.

Kindermann, G., McCallum, I., Fritz, S. and M. Obersteiner, 2008, A global forest growing stock, biomass and carbon map based on FAO statistics, Silva Fennica 42, 387-396.

Kindermann, G., Schorghuber, S., Linkosalo, T., et al., 2013, Potential stocks and increments of woody biomass in the European Union under different management and climate scenarios, Carbon Balance and Management 8:2.

Kocar, G. and N. Civas, 2013, An overview of biofuels from energy crops: Current status and future prospects, Renewable and Sustainable Energy Reviews 28, 900-916.

Lauri, P., Havlik, P., Kindermann, G., et al. 2014, Woody biomass energy potential in 2050, Energy Policy 66, 19-31.

Lindner, M., Fitzgerald, J., Zimmermann, N., et al., 2014, Climate change and European forests: What do we know, what are the uncertainties, and what are the implications for forest management? , Journal of Environmental Management 146, 69-83.

Lippke, B., Onell, E., Harrison, R., et al., 2011, Life cycle impacts of forest management and wood utilization on carbon mitigation: knowns and unknowns, Carbon Management 2(3), 303-333.

Mallo, M. and O. Espinoza, 2014, Outlook for cross-laminated timber in the United States, Bioresources 9(4), 7427-7443.

Mantau, U. et al., 2010, EUwood - Real potential for changes in growth and use of EU forests, Final report. Hamburg/Germany, June 2010.

Menon, V. and M. Rao, 2012, Trends in bioconversion of lignocellulose: biofuels, platform chemicals \& biorefinery concept, Progress in Energy and Combustion Science 38, 522-550.

OECD, 2015, Environment at a glance 2015: OECD indicators, OECD 2015.

Pachauri, S., van Ruijven, B., Nagai, Y., et al., 2013, Pathways to achieve universal household access to modern energy by 2030, Environmental Research Letters 8, 1-7. 
Perez-Garcia, J., Joyce, L, McGuire, A., et.al., 2002, Impacts of climate change on the global forest sector, Climate Chang 54, 439-461.

Raunikar, R., Buongiorno, J., Turner, J. and S. Zhu, 2010, Global outlook for wood and forests with the bioenergy demand implied by scenarios of the Intergovernmental Panel on Climate Change, Forest Policy and Economics 12, 48-56.

Riahi, K., van Vuuren, D., Kriegler, E., et al., 2017, The shared socioeconomic pathways and their energy, land use, and greenhouse gas emissions implications: An overview, Global Environmental Change 42, 153-168.

Rose, S., Kriegler, E., Bibas, R., et al., 2014, Bioenergy in energy transformation and climate management, Climate Change 123, 477-493.

Schulze, E., Körner, C., Law, B., et al., 2012, Large-scale bioenergy from additional harvest of forest biomass is neither sustainable nor greenhouse gas neutral, Global Change Biology Bioenergy 4, issue 6, 611-616.

Searle, S. and C. Malins, 2014, Will energy crop yields meet expectations? Biomass \& Bioenergy 65, 3-12.

Sedjo, R. and X. Tian, 2012, Does wood bioenergy increase carbon stocks in forests? Journal of Forestry 110: 304-311.

Sims, R., Hastings, A., Schlamadinger, B., et al., 2006, Energy crops: current status and future prospects, Global Change Biology 12, 2054-76.

Sleen, P., Groenendijk, P., Vlam, M., et al., 2015, No growth stimulation of tropical trees by 150 years of $\mathrm{CO}_{2}$ fertilization but water-use efficiency increased, Nature Geoscience 8, 2428.

Sohngen, B., Mendelsohn, R. and R. Sedjo, 1999, Forest management, conservation, and global timber markets, American Journal of Agricultural Economics, 81, 1-13.

Sohngen, B, and X. Tian, 2016, Global climate change impacts on forests and markets, Forest Policy and Economics 72, 18-26.

Tian, X., Sohngen, B., Kim, J., et al., 2016, Global climate change impacts on forests and markets, Environmental Research Letters 11, 1-10.

Verkerk, P., Anttila, P., Eggers, J., et al., 2011, The realizable potential supply of woody biomass from forests in the European Union, Forest Ecology and Management 261, 2007-15.

Vis, M., Mantau, U. and B. Allen, 2016, Study on the optimized cascading use of wood, Final Report, European Commission.

WBA, 2015, Global Bioenergy Statistics, World Bioenergy Association. 
Williams, J., 1995, The Epic model. In: Singh, V. (Ed.), Water Resources Publications, 9091000.

Zhou, L., Wang, S., Kindermann, G., et al., 2013, Carbon dynamics in woody biomass of forest ecosystem in China with forest management practices under future climate change and rising $\mathrm{CO}_{2}$ concentration, China Geographical Science 23, no. 5, 519-536.

\section{SUPPLEMENT}

\section{Formal description of the forest sector module}

This chapter includes a formal description of the forest sector module in GLOBIOM. The formal description of the full model (including agriculture sector and carbon emissions accounting) can be found in Havlik et al. (2011) and Havlik et al. (2014). The forest sector module is also described in Lauri et al. (2014) including a more detailed discussion on the assumptions of the model.

\subsection{Model structure}

Indexes

$\mathrm{i}, \mathrm{j}=$ =conomic regions

$\mathrm{k}=$ product

$\mathrm{f}=$ forest industry production activity

$\mathrm{h}=$ harvest activity

$\mathrm{r}=$ roundwood harvest activity $(\mathrm{r} \subset \mathrm{h})$

$\mathrm{l}=$ logging residues harvest activity $(\mathrm{l} \subset \mathrm{h})$

$\mathrm{m}, \mathrm{n}=$ land-use types

$\mathrm{o}=$ land-use unit

$\mathrm{t}=$ time (not used if same for all variables of the equation)

Variables

$\mathrm{W}=$ welfare

$\mathrm{x}=$ consumption quantity

$\mathrm{y}=$ production quantity

$\mathrm{e}=$ trade quantity

$\mathrm{z}=$ area of land-use change

$\mathrm{K}=$ capacity

$\mathrm{I}=$ investments

$\mathrm{L}=$ land area

Parameters 
$\mathrm{c}^{\text {tran }}=$ transport costs

$\mathrm{c}^{\mathrm{proc}}=$ process costs

$c^{\text {harv }}=$ harvest costs

$c^{\text {inv }}=$ investment costs

$\delta=$ depreciation rate

$\mathrm{a}=$ input-output coefficient

$\mathrm{b}=$ increment per area

$\mathrm{d}=$ biomass expansion factor

$\phi=$ recovery ratio

Functions

$\mathrm{D}(\mathrm{x})=$ inverse demand function

$\mathrm{C}^{\text {trade }}(\mathrm{e})=$ trade cost function

$\mathrm{C}^{\text {luc }}(\mathrm{z})=$ land-use change cost function

Objective function

$$
\begin{aligned}
\underset{x_{i k}, y_{i f}, y_{i h o}, e_{i j k}, z_{i m n o}, I_{i f}}{\operatorname{Wax}} & =\sum_{i k} \int_{0}^{x_{i k}} D_{i k}\left(x_{i k}\right) \mathrm{d} x_{i k}-\sum_{i h o} c_{i h o}^{\text {tran }} y_{i h o}-\sum_{i h o} c_{i h o}^{\text {harv }} y_{\text {iho }}-\sum_{i f} c_{i f}^{p r o c} y_{i f} \\
& -\sum_{i f} C_{i f}^{i n v} I_{i f}-\sum_{i j k} \int_{0}^{e_{i j k}} C_{i j k}^{\text {trade }}\left(e_{i j k}\right) d e_{i j k}-\sum_{i m n} \int_{0}^{z_{i m n}} C_{i m n}^{l u c}\left(\sum_{o} z_{i m n o}\right) d z_{i m n}
\end{aligned}
$$

subject to

$$
\begin{array}{lc}
x_{i k}-\sum_{f} a_{i f k} y_{i f}-\sum_{h o} a_{i h k} y_{i h o}-\sum_{j}\left(e_{i j k}-e_{j i k}\right) \leq 0 & \forall i, k \\
y_{\text {iro }} \leq \sum_{m} b_{\text {irmo }} L_{\text {rmo }} & \forall i, r, o \\
y_{\text {ilo }} \leq \sum_{r} \phi_{\text {irlo }} d_{\text {irlo }} y_{\text {iro }} & \forall i, l, o \\
y_{\text {if }} \leq K_{\text {if }} & \forall i, f \\
K_{\text {tif }}=(1-\delta) K_{(t-1) \text { if }}+I_{\text {tif }} & \forall i, f, t \\
L_{\text {timo }}=L_{(t-1) \text { imo }}+\sum_{n} z_{\text {tinmo }}-\sum_{n} z_{\text {timno }} & \forall i, m, o, t
\end{array}
$$


$y_{i f} \leq \sum_{k} \phi_{i f k} X_{i k}$

Equation (1) is the sum of consumers' and producers' surpluses. The first term of equation (1) is the area underneath the demand curve, which represents the value of final products consumption to the consumers. The remaining terms of equation (1) are the areas underneath the marginal cost curves, which represent the compensations paid to the producers. The second term is the transport costs of woody biomass from forest to the mill gate with in each region. The third term is the harvest costs of woody biomass. The fourth term is the process costs of woody biomass. The fifth term is the investment costs. The sixth term is the trade costs between the regions. The last term is the land-use change costs. Transport, harvest and land-use change costs are spatial explicit, i.e., they are indexed with regions i and land-use units o. Process, investment and trade costs are not spatially explicit, i.e., they are indexed with just with regions $\mathrm{i}$ (or $\mathrm{i}$ and $\mathrm{j}$ in case of trade costs).

Equation (2) is the material balance. It guarantees that products are not consumed or used as inputs in the production activities more than they are produced and traded. A production activity $\mathrm{f}$ uses product $\mathrm{k}$ as input if $\mathrm{a}_{\text {ifk }}<0$ and produces product $\mathrm{k}$ as output if $\mathrm{a}_{\text {ifk }}>0$. A harvest activity h produces just outputs, i.e., aihk $>0$.

Equations (3) and (4) determine the relationship between primary woody biomass supply and forest resources. Equation (3) is the roundwood harvest constraint. This equation ensures that roundwood harvests volumes do not exceed their harvest potential for each land-use unit. The harvest potential is based on the increment and forest area data from G4M. Equation (4) is the logging residues harvest constraint. This equation connects logging residues harvest volumes to roundwood harvest volumes and limit logging residues extraction to some share of their total volume in each land-use unit. The total volume of logging residues is based on the biomass expansion factors while the share of logging residues that is allowed to be extracted is on recovery ratio (Lauri et al. 2014). In the current version of the model the recovery ratio of logging residues is assumed to be 0.5 .

Equations (5) and (6) determine the relationship between production technologies and capital stock. Equation (5) is the capacity constraint. Equation (6) is capital accumulation constraint. Investments are undertaken as long as income of increasing capital stock is higher than the investment costs within each period. In the current version of the model the depreciation rate is assumed to be 0.3 in 10 -year period and is same for all final products.

Equation (7) is the land-use balance. Forestland decreases due to deforestation, i.e., changing forestland to cropland or grassland, and increases due to afforestation, i.e., changing cropland, grassland or other natural vegetation land to forestland. For sustainability reasons forestland is not allowed to be changed energy crops plantations. Within the forestland there are two land-use types: managed forests and unmanaged forests. In the forestland is used for production use then it is changed from unmanaged forest to managed forest.

Equation (8) limits recycled wood supply to a certain fraction of sawnwood, plywood and fiberboard consumption.

The one period social welfare maximization problem (1)-(8) is first calibrated and solved for the base year. Then it is solved repeatedly for the desired number of periods by assuming 
some exogenous or model history dependent changes in the state variables. The model period is 10 years. However, because the data are usually based on the one year periods, the state variables of the model are adapted to correspond one-year period.

Because the model is solved as a social welfare maximization problem, the objective function does not include any market prices or market clearing mechanism. Market prices for products $\mathrm{k}$ are obtained from the shadow prices of the material balance.

The model is solved using the GMS programming language and linear programming. Nonlinear functions are linearized using the piecewise-linear approximation.

\subsection{Final products inverse demand function}

Final products have constant elasticity inverse demand function

$$
D_{t i k}\left(x_{t i k}\right)=\bar{x}_{t i k}\left(\frac{p_{t i k}}{\bar{p}_{i k}}\right)^{\alpha_{k}} \quad \alpha_{k} \leq 0
$$

where $\mathrm{x}_{\mathrm{ik}}=$ quantity of demand for product $\mathrm{k}$ at region $\mathrm{i}$ in year $\mathrm{t}, \bar{x}_{i k}=$ =reference quantity of demand for product $\mathrm{k}$ at region $\mathrm{i}$ in year $\mathrm{t}, \mathrm{p}_{\mathrm{ik}}$ is price for product $\mathrm{k}$ at region $\mathrm{i}$ in year $\mathrm{t}$, $\bar{p}_{i k}=$ reference price for product $\mathrm{k}$ at region $\mathrm{i}$ and $\alpha_{\mathrm{k}}=$ price elasticity for product $\mathrm{k}$.

In the current version of the model price elasticities and reference prices are based on Buongiorno et al. (2003). Price elasticities vary in the range -0.1 to -0.5 depending on the product category. The reference price for exporting regions is the world export price and for importing regions the world export price plus transport costs. The world export price vary in the range 20 to $500 \$ / \mathrm{m} 3$. For simplicity the reference prices stay constant over time

Base year reference quantities are based on FAOSTAT data. After the base year reference quantities are shifted by population and GDP growth:

$$
\bar{x}_{(t+1) i k}=\bar{x}_{t i k}\left(\frac{p o p_{(t+1) i}}{p o p_{t i}}\right)\left(\frac{g d p_{(t+1) i}}{g d p_{t i}}\right)^{\beta_{i k g d p}} \quad \beta_{i k g d p}>0
$$

where pop $\mathrm{t}_{\mathrm{ti}}=$ population at region $\mathrm{i}$ in year $\mathrm{t}, \mathrm{gdp}_{\mathrm{ti}}=$ per capita gross domestic product (GDP) at region $\mathrm{i}$ in year $\mathrm{t}$ and $\beta_{\text {tigdp }}=$ GDP elasticity for product $\mathrm{k}$ at region $\mathrm{i}$ in year $\mathrm{t}$.

In the current version of the model GDP elasticities are assumed to be in the range 0.2 to 1 depending on the region, the product and the level of GDP. GDP elasticity depends on the level of GDP so that $\beta_{\text {lowincome }}>\beta_{\text {middleincome }}>\beta_{\text {highincome where income classes are based on }}$ World Bank classification. It follows that GDP elasticities of low income regions decrease over time, because their GDP increases and eventually they move to the higher income class.

In the SSP-RCP scenario calculations fuelwood demand phases out over time, which is modeled by decreasing reference quantity over time rather than of shifting it by population and GDP growth. 
Total biomass demand for energy is assumed to be perfectly inelastic $(\alpha=0)$, which means that total biomass demand for energy wood depends only on the reference quantity (=fixed quantity demand). The reference quantities for total biomass demand for energy are taken from SSP-RCP scenario calculations.

\subsection{Trade cost function}

Trade costs are modeled using a constant elasticity trade cost function

$$
C_{t i j k}^{t r a d e}\left(e_{t i j k}\right)=\bar{C}_{k}\left(\frac{e_{t i j k}}{\bar{e}_{t i j k}}\right)^{\varepsilon} \quad \varepsilon \geq 0
$$

where $\mathrm{e}_{\mathrm{tijk}}=$ trade quantity for product $\mathrm{k}$ from region $\mathrm{i}$ to region $\mathrm{j}$ in year $\mathrm{t}, \bar{e}_{t i j k}=$ reference trade quantity for product $\mathrm{k}$ from region $\mathrm{i}$ to region $\mathrm{j}$ in year $\mathrm{t}, \bar{c}_{k}=$ reference trade costs for product $\mathrm{k}$ and $\varepsilon=$ trade elasticity.

In the current version of the model trade elasticity is assumed to be 0.5 , which is same for all products and regions. Reference trade costs are based on Buongiorno et al. (2003) and they vary in the range 20 to $80 \$ / \mathrm{m} 3$ or ton depending on the product. For simplicity the reference trade costs stay constant over time and they are same for all regions.

The base year reference trade quantities for based on BACI bilateral trade database (Gaulier and Zignago 2010). After the base year the reference trade quantity is assumed to be previous period trade quantity:

$$
\bar{e}_{(t+1) i j k}=e_{t i j k}
$$

If there is no trade in the previous year then it is assumed that trade costs are linearly increasing function of the periodic trade quantity (similar to the land-use change cost function).

\subsection{Land-use change cost function}

Land-use change costs are modeled using a linearly increasing cost function

$$
C_{i m n}^{\text {luc }}\left(Z_{\text {timn }}\right)=\bar{c}_{i m n}+\eta_{i m n} Z_{\text {timn }} \quad \eta_{\text {imn }}>0
$$

where $\mathrm{z}_{\text {timn }}=$ area of land-use change from land type $\mathrm{m}$ to land type $\mathrm{n}$ at region $\mathrm{i}$ in period $\mathrm{t}$, $\bar{c}_{i m n}=$ fixed cost land-use change from land type $\mathrm{m}$ to land type $\mathrm{n}$ at region $\mathrm{i}$ and $\eta_{\text {imn }}=$ slope of land-use change cost function from land type $m$ to land type $n$ at region $i$.

The parameters of land-use change cost function are based on historical land-use change patterns. In the current version of the model the fixed costs of changing unmanaged forest to managed forest is $80 \$ /$ ha and the slope $0.05 \$ /$ ha, the fixed costs of changing unmanaged forest to crop land is zero and the slope varies in range 0.01 to $0.2 \$ /$ ha and the fixed costs of changing unmanaged forest to grass land is zero and the slope varies in range 0.005 to 0.02 \$/ha. 
Remark that land-use change costs are an increasing function of accumulated land-use change during the whole 10 year period.

\subsection{Calibration of the model and consistency checks}

The current version of the forest sector module uses the following calibration and consistency check methods. First, the consistency between harvest potentials and FAOSTAT harvest volumes is checked. If the FAOSTAT harvest volumes exceeds the harvest potential in some region, then the harvest potential is increased in this region. Second, the consistence between model production technologies and FAOSTAT production/consumption quantities is checked. If the regional and global material balances based on the model production technologies and FAOSTAT production/consumption quantities do not match, then FAOSTAT production/consumption quantities is changed so that the material balances hold. The changes are based on the goal programming, which minimize the weighted sum of deviations. Remark that the consistency check chances FAOSTAT production/consumption quantities instead of production technology parameters. Hence, the model production/consumption quantities might differ slightly from the FAOSTAT production/consumption quantities. This is because the model uses representative best available technologies (BAT), which are same for all regions and which stay unchanged over time. Third, the consistency between BACI bilateral trade quantities and FAOSTAT net trade quantities is checked. If BACI bilateral trade quantities do not sum up to FAOSTAT net trade quantities at regional and global level, the BACI bilateral trade quantities are changed so that they sum up to FAOSTAT net trade quantities. The changes are based on the goal programming, which minimize the weighted sum of deviations. Fourth, final products production quantities is forced to FAOSTAT production quantities by setting the base year capacities are equal to FAOSTAT production quantities. Fifth, final products demand quantities are forced to FAOSTAT consumption quantities by setting the base year reference quantities in demand functions equal to FAOSTAT consumption quantities. Sixth, bilateral trade quantities are forced to BACI bilateral trade quantities by setting the base year reference quantities in trade cost functions equal to BACI bilateral trade quantities. Seventh, production technology parameters that define the shares of pulplogs and by-products in pulp and fiberboard production are calibrated so that they are consistent with FAOSTAT pulplogs consumption quantities.

The base year of the model is usually 2000. In this study, we extend to base-year to 2010 by assuming that period 2010 capacities and references quantities of demand functions are based on the FAOSTAT data.

\section{Numerical results for figures 3-8}

\subsection{Figure 3: Cost-supply curves}

The global cost-supply curves in Figure 3 are calculated by assuming that all regions face a same fixed price demand function, which eliminates the trade motive. In the actual scenario calculations each region faces separate demand functions and trade costs, which tends to increase prices compared to the global cost-supply curve. Moreover, it is assumed that fixed prices demand functions stay unchanged over time. In actual scenario calculations demand increases over time. That is why woody biomass prices in Figure 7 are not directly 
comparable to the cost-supply curves in Figure 3. In cost-supply curves roundwood is measured as over bark (o.b.).

\begin{tabular}{|c|c|c|c|c|c|c|c|c|c|c|c|c|c|c|c|c|c|c|c|c|c|}
\hline Figure 3 & & & & & & & & & & & & & & & & & & & & & \\
\hline \multicolumn{22}{|c|}{ Cost-supply curve $2010(\mathrm{Gm} 3, \$ / \mathrm{m} 3)$} \\
\hline & 0 & 10 & 20 & 30 & 40 & 50 & 60 & 70 & 80 & 90 & 100 & 110 & 120 & 130 & 140 & 150 & 160 & 170 & 180 & 190 & 200 \\
\hline roundwood & 0.0 & 0.0 & 0.0 & 1.6 & 3.2 & 3.8 & 4.5 & 5.0 & 5.5 & 5.9 & 6.2 & 6.7 & 7.0 & 7.3 & 7.5 & 7.9 & 8.1 & 8.3 & 8.6 & 8.8 & 9.1 \\
\hline loggingresidues & 0.0 & 0.0 & 0.0 & 0.6 & 1.2 & 1.4 & 1.7 & 1.9 & 2.0 & 2.2 & 2.3 & 2.5 & 2.6 & 2.7 & 2.8 & 2.9 & 3.0 & 3.1 & 3.2 & 3.3 & 3.4 \\
\hline & & & & & & & & & & & & & & & & & & & & & \\
\hline \multicolumn{22}{|c|}{ Cost-supply curve $2100(\mathrm{Gm} 3, \$ / \mathrm{m} 3)$} \\
\hline & 0 & 10 & 20 & 30 & 40 & 50 & 60 & 70 & 80 & 90 & 100 & 110 & 120 & 130 & 140 & 150 & 160 & 170 & 180 & 190 & 200 \\
\hline roundwood & 0.0 & 0.0 & 0.0 & 1.6 & 4.4 & 6.0 & 7.9 & 9.3 & 10.2 & 11.2 & 11.9 & 12.8 & 13.3 & 13.8 & 14.4 & 14.8 & 15.1 & 15.3 & 15.5 & 15.6 & 15.9 \\
\hline loggingresidues & 0.0 & 0.0 & 0.0 & 0.6 & 1.6 & 2.2 & 2.9 & 3.5 & 3.8 & 4.2 & 4.4 & 4.7 & 4.9 & 5.1 & 5.4 & 5.5 & 5.6 & 5.7 & 5.8 & 5.8 & 5.9 \\
\hline
\end{tabular}

\subsection{Figure 4: Total biomass use for energy}

The total biomass use for energy in terms of primary energy is taken as given from SSP-RCP scenarios runs while the division between energy crops, other biomass and woody biomass is based on GLOBIOM model outcome. Woody biomass volumes are converted to energy units using factor $1 \mathrm{GJ}=7.2 \mathrm{~m} 3$, which is based on net heating value $16 \mathrm{GJ} / \mathrm{t}$ and basic density 0.45 $\mathrm{t} / \mathrm{m} 3$. The net heating value of oven dry ( $0 \%$ moisture) wood is about $19 \mathrm{GJ} / \mathrm{t}$ and decreases to $8 \mathrm{GJ} / \mathrm{t}$ for fresh (50\% moisture) wood (IEA 2005, VTT 2016). As woody biomass used for energy is usually air-dried, we chose to use the net heating value of air-dry (10-20\% moisture) wood of $16 \mathrm{GJ} / \mathrm{t}$. The basic density of woody biomass varies in the range of 0.2-1.0 $\mathrm{t} / \mathrm{m} 3$ across tree species, tree parts and regions (IPCC 2006, VTT 2016). For simplicity and transparency, we used the same average density of $0.45 \mathrm{t} / \mathrm{m} 3$ for all woody biomass in the energy conversion, as it would be extremely complicated to keep track of different tree species and woody biomass types along the woody biomass transformation path from forest to energy.

\begin{tabular}{|c|c|c|c|c|c|c|c|c|c|c|}
\hline Figure 4 & & & & & & & & & & \\
\hline \multicolumn{11}{|c|}{ Total biomass use for energy RCPref (EJ) } \\
\hline & 2010 & 2020 & 2030 & 2040 & 2050 & 2060 & 2070 & 2080 & 2090 & 2100 \\
\hline energy crops and other biomass & 31.0 & 34.9 & 36.6 & 38.2 & 39.9 & 41.7 & 43.6 & 45.1 & 46.0 & 46.9 \\
\hline woody biomass & 23.0 & 22.5 & 22.1 & 21.5 & 20.9 & 20.1 & 19.2 & 18.6 & 18.8 & 19.5 \\
\hline total & 54.0 & 57.4 & 58.6 & 59.6 & 60.9 & 61.8 & 62.8 & 63.7 & 64.7 & 66.4 \\
\hline \multicolumn{11}{|c|}{ Total biomass use for energy RCP2.6 (EJ) } \\
\hline & 2010 & 2020 & 2030 & 2040 & 2050 & 2060 & 2070 & 2080 & 2090 & 2100 \\
\hline energy crops and other biomass & 31.0 & 41.8 & 47.6 & 53.5 & 62.9 & 76.0 & 98.0 & 120.8 & 138.9 & 150.6 \\
\hline woody biomass & 23.0 & 22.7 & 22.7 & 22.6 & 25.1 & 27.7 & 31.3 & 36.6 & 45.8 & 56.3 \\
\hline total & 54.0 & 64.5 & 70.3 & 76.1 & 88.0 & 103.7 & 129.3 & 157.5 & 184.7 & 206.9 \\
\hline
\end{tabular}

\subsection{Figure 5: Woody biomass use for energy}

Woody biomass use for energy is measured by the amount of primary products and byproducts that is used for energy production in terms of primary energy. Thus, we do not consider explicitly liquid biofuels, pellets and char coal production in this version of the model. Roundwood includes pulplogs and sawlogs that are used for industrial sector energy production. In woody biomass energy use fuelwood and roundwood are measured as over bark, because bark is not removed from roundwood when it is used for energy. By-products include bark (from roundwood material use), sawdust, woodchips, black liquor and recycled 
wood. All woody biomass use for energy is measured in terms of oven dry wood $\mathrm{m}^{3}$. Black liquor is measured on its woody biomass content.

\begin{tabular}{|c|c|c|c|c|c|c|c|c|c|c|}
\hline Figure $5 a$ & & & & & & & & & & \\
\hline \multicolumn{11}{|c|}{ Woody biomass use for energy RCPref (Gm3) } \\
\hline & 2010 & 2020 & 2030 & 2040 & 2050 & 2060 & 2070 & 2080 & 2090 & 2100 \\
\hline fuelwood & 2.13 & 1.77 & 1.48 & 1.16 & 0.87 & 0.55 & 0.22 & 0.00 & 0.00 & 0.00 \\
\hline by-products & 1.00 & 1.26 & 1.49 & 1.72 & 1.92 & 2.08 & 2.25 & 2.39 & 2.50 & 2.58 \\
\hline loggingresidues & 0.07 & 0.10 & 0.10 & 0.11 & 0.12 & 0.17 & 0.20 & 0.20 & 0.11 & 0.13 \\
\hline roundwood & 0.00 & 0.00 & 0.00 & 0.00 & 0.00 & 0.00 & 0.00 & 0.00 & 0.00 & 0.00 \\
\hline total & 3.20 & 3.13 & 3.07 & 2.98 & 2.91 & 2.80 & 2.66 & 2.58 & 2.61 & 2.71 \\
\hline & & & & & & & & & & \\
\hline \multicolumn{11}{|c|}{ Woody biomass use for energy RCP2.6 (Gm3 o.b.) } \\
\hline & 2010 & 2020 & 2030 & 2040 & 2050 & 2060 & 2070 & 2080 & 2090 & 2100 \\
\hline fuelwood & 2.13 & 1.77 & 1.47 & 1.16 & 0.86 & 0.54 & 0.22 & 0.00 & 0.00 & 0.00 \\
\hline by-products & 1.00 & 1.27 & 1.51 & 1.74 & 1.95 & 2.15 & 2.38 & 2.57 & 2.69 & 2.76 \\
\hline loggingresidues & 0.07 & 0.12 & 0.18 & 0.24 & 0.68 & 1.16 & 1.60 & 1.88 & 2.23 & 2.64 \\
\hline roundwood & 0.00 & 0.00 & 0.00 & 0.00 & 0.00 & 0.00 & 0.15 & 0.64 & 1.44 & 2.43 \\
\hline total & 3.20 & 3.15 & 3.16 & 3.14 & 3.49 & 3.85 & 4.35 & 5.09 & 6.36 & 7.82 \\
\hline
\end{tabular}

\begin{tabular}{|c|c|c|c|c|c|c|c|c|c|c|}
\hline Figure $5 b$ & & & & & & & & & & \\
\hline \multicolumn{11}{|c|}{ Woody biomass use for energy RCPref (Gm3) } \\
\hline & 2010 & 2020 & 2030 & 2040 & 2050 & 2060 & 2070 & 2080 & 2090 & 2100 \\
\hline Russia & 0.20 & 0.21 & 0.22 & 0.21 & 0.21 & 0.20 & 0.19 & 0.19 & 0.19 & 0.19 \\
\hline EU28 & 0.32 & 0.32 & 0.31 & 0.31 & 0.30 & 0.30 & 0.29 & 0.29 & 0.29 & 0.30 \\
\hline North-America & 0.30 & 0.30 & 0.30 & 0.31 & 0.31 & 0.32 & 0.32 & 0.33 & 0.33 & 0.34 \\
\hline South-America & 0.49 & 0.48 & 0.47 & 0.47 & 0.46 & 0.49 & 0.48 & 0.48 & 0.46 & 0.49 \\
\hline Asia & 1.13 & 1.14 & 1.12 & 1.08 & 1.04 & 0.95 & 0.86 & 0.79 & 0.81 & 0.82 \\
\hline Africa & 0.76 & 0.69 & 0.64 & 0.61 & 0.58 & 0.55 & 0.53 & 0.52 & 0.54 & 0.59 \\
\hline World & 3.19 & 3.13 & 3.06 & 2.98 & 2.91 & 2.80 & 2.66 & 2.58 & 2.61 & 2.71 \\
\hline \multirow{2}{*}{\multicolumn{11}{|c|}{ Woody biomass use for energy RCP2.6 (Gm3) }} \\
\hline & & & & & & & & & & \\
\hline & 2010 & 2020 & 2030 & 2040 & 2050 & 2060 & 2070 & 2080 & 2090 & 2100 \\
\hline Russia & 0.20 & 0.21 & 0.22 & 0.22 & 0.21 & 0.21 & 0.23 & 0.27 & 0.32 & 0.37 \\
\hline EU28 & 0.32 & 0.32 & 0.32 & 0.31 & 0.34 & 0.42 & 0.50 & 0.53 & 0.58 & 0.60 \\
\hline North-America & 0.30 & 0.30 & 0.31 & 0.31 & 0.32 & 0.37 & 0.56 & 0.62 & 0.68 & 0.82 \\
\hline South-America & 0.49 & 0.49 & 0.54 & 0.59 & 0.65 & 0.67 & 0.75 & 0.99 & 1.39 & 1.85 \\
\hline Asia & 1.13 & 1.14 & 1.12 & 1.09 & 1.33 & 1.43 & 1.46 & 1.61 & 1.96 & 2.36 \\
\hline Africa & 0.76 & 0.69 & 0.66 & 0.64 & 0.64 & 0.74 & 0.86 & 1.07 & 1.42 & 1.82 \\
\hline World & 3.19 & 3.15 & 3.17 & 3.15 & 3.49 & 3.84 & 4.34 & 5.08 & 6.35 & 7.82 \\
\hline
\end{tabular}




\begin{tabular}{|l|r|r|r|r|r|r|r|r|r|r|r|}
\hline Figure 5c & & & & & & & \\
\hline Woody biomass use for energy in boreal zone RCP2.6(Gm3) & & & & & \\
\hline
\end{tabular}

\subsection{Figure 6: Woody biomass material use}

In Figure 6a woody biomass material use is measured by the amount of primary products and by-products that is used for final material products production. In Figure 6b woody biomass material use is measured in terms of final material products production. Final material products are usually measured in different units (sawnwood, plywood, fibreboard and other industrial roundwood by $\mathrm{m}^{3}$ and chemical pulp and mechanical pulp by ton). In Figure $6 \mathrm{~b}$ we use the roundwood equivalent units (RWeq) to make them comparable to each other. This means that final material products are measured in terms of their raw material consumption instead of their actual volume. The conversion between these units is based on the production technologies that the model uses. Sawlogs, pulplogs and other industrial roundwood is measured as under bark, because bark is removed when they are used for material production. 
Figure 6a

Woody biomass material use RCPref (Gm3)

\begin{tabular}{|c|c|c|c|c|c|c|c|c|c|c|}
\hline \\
\hline & 2010 & 2020 & 2030 & 2040 & 2050 & 2060 & 2070 & 2080 & 2090 & 2100 \\
\hline sawlogs & 0.95 & 1.24 & 1.51 & 1.76 & 1.98 & 2.17 & 2.36 & 2.53 & 2.67 & 2.77 \\
\hline pulplogs & 0.63 & 0.72 & 0.81 & 0.87 & 0.93 & 0.97 & 0.99 & 1.01 & 1.02 & 1.02 \\
\hline by-products & 0.33 & 0.42 & 0.49 & 0.55 & 0.60 & 0.64 & 0.67 & 0.71 & 0.73 & 0.74 \\
\hline other ind rw & 0.15 & 0.14 & 0.14 & 0.14 & 0.14 & 0.14 & 0.14 & 0.14 & 0.14 & 0.14 \\
\hline total & 2.05 & 2.52 & 2.95 & 3.33 & 3.64 & 3.91 & 4.17 & 4.39 & 4.55 & 4.68 \\
\hline & & & & & & & & & & \\
\hline \multicolumn{11}{|c|}{ Woody biomass material use RCP2.6 (Gm3) } \\
\hline & 2010 & 2020 & 2030 & 2040 & 2050 & 2060 & 2070 & 2080 & 2090 & 2100 \\
\hline sawlogs & 0.95 & 1.25 & 1.52 & 1.77 & 2.00 & 2.22 & 2.47 & 2.67 & 2.80 & 2.88 \\
\hline pulplogs & 0.63 & 0.72 & 0.81 & 0.88 & 0.94 & 0.99 & 1.03 & 1.05 & 1.06 & 1.05 \\
\hline by-products & 0.33 & 0.41 & 0.49 & 0.55 & 0.59 & 0.62 & 0.65 & 0.66 & 0.66 & 0.65 \\
\hline other ind rw & 0.15 & 0.14 & 0.14 & 0.14 & 0.14 & 0.14 & 0.14 & 0.14 & 0.14 & 0.13 \\
\hline total & 2.05 & 2.53 & 2.96 & 3.34 & 3.67 & 3.97 & 4.28 & 4.52 & 4.65 & 4.72 \\
\hline & & & & & & & & & & \\
\hline \multicolumn{11}{|c|}{ Woody biomass material use difference between RCP2.6 and RCpref (Mm3) } \\
\hline & 2010 & 2020 & 2030 & 2040 & 2050 & 2060 & 2070 & 2080 & 2090 & 2100 \\
\hline sawlogs & 0 & 8 & 10 & 15 & 25 & 54 & 108 & 138 & 134 & 113 \\
\hline pulplogs & 0 & 4 & 6 & 9 & 10 & 19 & 33 & 42 & 37 & 26 \\
\hline by-products & 0 & -3 & -5 & -6 & -10 & -15 & -28 & -48 & -68 & -88 \\
\hline other ind rw & 0 & 0 & 0 & 0 & 0 & 1 & 0 & -2 & -6 & -9 \\
\hline total material use & 0 & 9 & 11 & 18 & 25 & 59 & 113 & 130 & 97 & 42 \\
\hline
\end{tabular}

Figure 6b

Woody biomass material use RCPref (Gm3 RWeq)

\begin{tabular}{|c|c|c|c|c|c|c|c|c|c|c|}
\hline \multirow{2}{*}{\multicolumn{11}{|c|}{ | }} \\
\hline & 2010 & 2020 & 2030 & 2040 & 2050 & 2060 & 2070 & 2080 & 2090 & 2100 \\
\hline Sawnwood & 0.76 & 0.99 & 1.19 & 1.39 & 1.56 & 1.71 & 1.87 & 2.01 & 2.11 & 2.20 \\
\hline Plywood & 0.18 & 0.25 & 0.31 & 0.37 & 0.42 & 0.45 & 0.49 & 0.53 & 0.55 & 0.57 \\
\hline Fiberboard & 0.27 & 0.35 & 0.42 & 0.47 & 0.51 & 0.54 & 0.57 & 0.59 & 0.61 & 0.62 \\
\hline ChemPulp & 0.62 & 0.71 & 0.80 & 0.87 & 0.92 & 0.96 & 0.99 & 1.01 & 1.02 & 1.03 \\
\hline MechPulp & 0.07 & 0.07 & 0.08 & 0.09 & 0.10 & 0.10 & 0.11 & 0.11 & 0.11 & 0.12 \\
\hline Other ind rw & 0.15 & 0.14 & 0.14 & 0.14 & 0.14 & 0.14 & 0.14 & 0.14 & 0.14 & 0.14 \\
\hline total & 2.05 & 2.52 & 2.95 & 3.33 & 3.64 & 3.91 & 4.17 & 4.39 & 4.55 & 4.68 \\
\hline \multicolumn{11}{|c|}{ Woody biomass material use RCP2.6 (Gm3 RWeq) } \\
\hline & 2010 & 2020 & 2030 & 2040 & 2050 & 2060 & 2070 & 2080 & 2090 & 2100 \\
\hline Sawnwood & 0.76 & 1.00 & 1.20 & 1.40 & 1.58 & 1.76 & 1.96 & 2.12 & 2.23 & 2.30 \\
\hline Plywood & 0.18 & 0.26 & 0.32 & 0.37 & 0.42 & 0.46 & 0.51 & 0.55 & 0.57 & 0.58 \\
\hline Fiberboard & 0.27 & 0.35 & 0.42 & 0.47 & 0.50 & 0.53 & 0.55 & 0.56 & 0.56 & 0.55 \\
\hline ChemPulp & 0.62 & 0.72 & 0.80 & 0.87 & 0.93 & 0.97 & 1.01 & 1.04 & 1.05 & 1.03 \\
\hline MechPulp & 0.07 & 0.07 & 0.08 & 0.09 & 0.10 & 0.10 & 0.11 & 0.11 & 0.11 & 0.11 \\
\hline Other ind rw & 0.15 & 0.14 & 0.14 & 0.14 & 0.14 & 0.14 & 0.14 & 0.14 & 0.14 & 0.13 \\
\hline total & 2.05 & 2.53 & 2.96 & 3.34 & 3.67 & 3.97 & 4.28 & 4.52 & 4.65 & 4.72 \\
\hline \multicolumn{11}{|c|}{ Woody biomass material use difference between RCP2.6 and RCpref (Mm3 RWeq) } \\
\hline & 2010 & 2020 & 2030 & 2040 & 2050 & 2060 & 2070 & 2080 & 2090 & 2100 \\
\hline Sawnwood & 0 & 7 & 9 & 12 & 23 & 47 & 94 & 118 & 117 & 98 \\
\hline ChemPulp & 0 & 1 & 1 & 3 & 2 & 7 & 14 & 20 & 17 & 14 \\
\hline MechPulp & 0 & -2 & -2 & -3 & -5 & -8 & -16 & -33 & -49 & -64 \\
\hline Plywood & 0 & 3 & 4 & 6 & 5 & 13 & 20 & 28 & 21 & 6 \\
\hline Fiberboard & 0 & 0 & 0 & 0 & 0 & 0 & 0 & -1 & -2 & -4 \\
\hline Other ind rw & 0 & 0 & 0 & 0 & 0 & 1 & 0 & -2 & -6 & -9 \\
\hline total material use & 0 & 10 & 12 & 17 & 26 & 59 & 112 & 131 & 97 & 41 \\
\hline
\end{tabular}


Figure 6c

Woody biomass material use RCPref $(\mathrm{Gm} 3)$

\begin{tabular}{|c|c|c|c|c|c|c|c|c|c|c|}
\hline \multicolumn{11}{|l|}{ - } \\
\hline 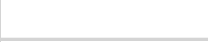 & 2010 & 2020 & 2030 & 2040 & 2050 & 2060 & 2070 & 2080 & 2090 & 2100 \\
\hline Russia & 0.16 & 0.17 & 0.20 & 0.20 & 0.21 & 0.21 & 0.22 & 0.22 & 0.23 & 0.23 \\
\hline EU28 & 0.45 & 0.48 & 0.51 & 0.54 & 0.56 & 0.59 & 0.61 & 0.63 & 0.65 & 0.66 \\
\hline North-America & 0.57 & 0.61 & 0.65 & 0.69 & 0.72 & 0.76 & 0.79 & 0.82 & 0.85 & 0.86 \\
\hline South-America & 0.22 & 0.31 & 0.38 & 0.44 & 0.49 & 0.55 & 0.61 & 0.67 & 0.72 & 0.76 \\
\hline Asia & 0.59 & 0.81 & 1.00 & 1.16 & 1.27 & 1.34 & 1.40 & 1.44 & 1.46 & 1.47 \\
\hline Africa & 0.07 & 0.14 & 0.21 & 0.30 & 0.39 & 0.46 & 0.54 & 0.60 & 0.66 & 0.70 \\
\hline World & 2.05 & 2.52 & 2.95 & 3.33 & 3.64 & 3.91 & 4.17 & 4.39 & 4.55 & 4.67 \\
\hline \multirow{2}{*}{\multicolumn{11}{|c|}{ Woody biomass material use RCP2.6 (Gm3) }} \\
\hline & & & & & & & & & & \\
\hline & 2010 & 2020 & 2030 & 2040 & 2050 & 2060 & 2070 & 2080 & 2090 & 2100 \\
\hline Russia & 0.16 & 0.17 & 0.20 & 0.21 & 0.21 & 0.22 & 0.24 & 0.26 & 0.26 & 0.27 \\
\hline EU28 & 0.45 & 0.48 & 0.51 & 0.54 & 0.56 & 0.59 & 0.62 & 0.65 & 0.67 & 0.69 \\
\hline North-America & 0.57 & 0.61 & 0.65 & 0.68 & 0.72 & 0.75 & 0.79 & 0.84 & 0.89 & 0.90 \\
\hline South-America & 0.22 & 0.32 & 0.39 & 0.45 & 0.51 & 0.58 & 0.64 & 0.68 & 0.70 & 0.73 \\
\hline Asia & 0.59 & 0.81 & 1.00 & 1.17 & 1.28 & 1.36 & 1.45 & 1.49 & 1.49 & 1.47 \\
\hline Africa & 0.07 & 0.14 & 0.21 & 0.30 & 0.40 & 0.48 & 0.55 & 0.60 & 0.64 & 0.67 \\
\hline World & 2.05 & 2.53 & 2.96 & 3.34 & 3.67 & 3.97 & 4.28 & 4.52 & 4.65 & 4.72 \\
\hline \multicolumn{11}{|c|}{ Woody biomass material use difference between RCP2.6 and RCpref (Mm3) } \\
\hline & 2010 & 2020 & 2030 & 2040 & 2050 & 2060 & 2070 & 2080 & 2090 & 2100 \\
\hline Russia & 0 & 0 & 3 & 4 & 5 & 4 & 16 & 33 & 38 & 41 \\
\hline South-America & 0 & 3 & 3 & 6 & 15 & 25 & 29 & 8 & -14 & -31 \\
\hline North-America & 0 & 1 & 0 & -2 & -5 & -6 & -4 & 23 & 41 & 47 \\
\hline EU27 & 0 & 2 & 1 & 2 & 1 & 2 & 10 & 19 & 26 & 29 \\
\hline Asia & 0 & 4 & 4 & 5 & 4 & 18 & 51 & 49 & 26 & -7 \\
\hline Africa & 0 & 1 & -2 & 2 & 7 & 17 & 16 & -1 & -19 & -36 \\
\hline World & 0 & 11 & 9 & 17 & 27 & 60 & 118 & 131 & 98 & 43 \\
\hline
\end{tabular}

\subsection{Figure 7: Woody biomass prices}

\begin{tabular}{|c|c|c|c|c|c|c|c|c|c|c|}
\hline \multicolumn{11}{|c|}{ Woody biomass prices RCPref (\$/m3) } \\
\hline & 2010 & 2020 & 2030 & 2040 & 2050 & 2060 & 2070 & 2080 & 2090 & 2100 \\
\hline sawlogs & 64 & 80 & 81 & 78 & 81 & 84 & 86 & 85 & 81 & 78 \\
\hline pulplogs & 46 & 60 & 65 & 66 & 68 & 70 & 71 & 68 & 66 & 64 \\
\hline By-products and Ic & 19 & 21 & 19 & 20 & 20 & 20 & 21 & 21 & 20 & 20 \\
\hline \multirow{2}{*}{\multicolumn{11}{|c|}{ Woody biomass prices RCP2.6 (\$/m3) }} \\
\hline & & & & & & & & & & \\
\hline & 2010 & 2020 & 2030 & 2040 & 2050 & 2060 & 2070 & 2080 & 2090 & 2100 \\
\hline & & & & & & & & & & \\
\hline sawlogs & 64 & 80 & 81 & 78 & 80 & 81 & 84 & 90 & 102 & 117 \\
\hline pulplogs & 46 & 60 & 65 & 65 & 67 & 68 & 69 & 74 & 85 & 100 \\
\hline By-products and Ic & 19 & 24 & 23 & 24 & 27 & 32 & 46 & 60 & 73 & 88 \\
\hline
\end{tabular}




\subsection{Figure 8: Harvest volumes and intensity of use of forest resources}

Roundwood harvest volume is sum over sawlogs, pulplogs, fuelwood and other industrial roundwood production and it is measured over bark.

\begin{tabular}{|l|r|r|r|r|r|r|r|r|r|r|r|}
\hline Figure 8a & & & \\
\hline Roundwood harvest volumes and harvest potential RCPref (Gm3 o.b.) & & & \\
\hline
\end{tabular}

Figure 8b

Roundwood harvest volumes RCPref (Gm3 o.b.)

\begin{tabular}{|c|c|c|c|c|c|c|c|c|c|c|}
\hline \\
\hline & 2010 & 2020 & 2030 & 2040 & 2050 & 2060 & 2070 & 2080 & 2090 & 2100 \\
\hline Russia & 0.26 & 0.27 & 0.28 & 0.27 & 0.26 & 0.26 & 0.25 & 0.25 & 0.25 & 0.25 \\
\hline EU28 & 0.49 & 0.51 & 0.52 & 0.52 & 0.52 & 0.53 & 0.54 & 0.54 & 0.55 & 0.56 \\
\hline North-America & 0.56 & 0.58 & 0.6 & 0.62 & 0.63 & 0.65 & 0.67 & 0.68 & 0.7 & 0.71 \\
\hline South-America & 0.55 & 0.61 & 0.65 & 0.66 & 0.68 & 0.69 & 0.71 & 0.75 & 0.8 & 0.85 \\
\hline Asia & 1.36 & 1.43 & 1.47 & 1.49 & 1.47 & 1.4 & 1.31 & 1.25 & 1.27 & 1.28 \\
\hline Africa & 0.76 & 0.76 & 0.75 & 0.75 & 0.76 & 0.74 & 0.71 & 0.71 & 0.77 & 0.82 \\
\hline World & 3.98 & 4.16 & 4.27 & 4.31 & 4.32 & 4.27 & 4.19 & 4.18 & 4.34 & 4.47 \\
\hline \multicolumn{11}{|c|}{ Roundwood harvest volumes RCP2.6 (Gm3 o.b.) } \\
\hline & 2010 & 2020 & 2030 & 2040 & 2050 & 2060 & 2070 & 2080 & 2090 & 2100 \\
\hline Russia & 0.26 & 0.27 & 0.28 & 0.27 & 0.27 & 0.26 & 0.27 & 0.31 & 0.35 & 0.39 \\
\hline EU28 & 0.49 & 0.51 & 0.52 & 0.52 & 0.53 & 0.53 & 0.55 & 0.58 & 0.62 & 0.64 \\
\hline North-America & 0.56 & 0.58 & 0.6 & 0.62 & 0.63 & 0.65 & 0.68 & 0.73 & 0.79 & 0.89 \\
\hline South-America & 0.55 & 0.62 & 0.66 & 0.67 & 0.69 & 0.72 & 0.79 & 0.97 & 1.27 & 1.62 \\
\hline Asia & 1.36 & 1.44 & 1.47 & 1.5 & 1.48 & 1.42 & 1.39 & 1.47 & 1.71 & 1.99 \\
\hline Africa & 0.76 & 0.76 & 0.76 & 0.77 & 0.77 & 0.76 & 0.82 & 0.97 & 1.22 & 1.52 \\
\hline World & 3.98 & 4.18 & 4.29 & 4.35 & 4.37 & 4.34 & 4.5 & 5.03 & 5.96 & 7.05 \\
\hline
\end{tabular}

\begin{tabular}{|c|c|c|c|c|c|c|c|c|c|c|}
\hline Figure $8 c$ & & & & & & & & & & \\
\hline \multicolumn{11}{|c|}{ Intensity of use of forest resources RCPref (\%) } \\
\hline & 2010 & 2020 & 2030 & 2040 & 2050 & 2060 & 2070 & 2080 & 2090 & 2100 \\
\hline Russia & 12 & 12 & 12 & 12 & 12 & 12 & 11 & 11 & 11 & 11 \\
\hline EU28 & 73 & 76 & 77 & 77 & 77 & 79 & 80 & 80 & 82 & 83 \\
\hline North-America & 17 & 18 & 19 & 19 & 20 & 20 & 21 & 21 & 22 & 22 \\
\hline South-America & 10 & 11 & 12 & 12 & 12 & 13 & 13 & 14 & 15 & 16 \\
\hline Asia & 43 & 45 & 47 & 48 & 48 & 46 & 43 & 42 & 42 & 43 \\
\hline Africa & 18 & 18 & 19 & 19 & 20 & 20 & 20 & 20 & 22 & 24 \\
\hline World & 21 & 22 & 23 & 23 & 23 & 23 & 22 & 22 & 23 & 24 \\
\hline \multicolumn{11}{|c|}{ Intensity of use of forest resources RCP2.6 (\%) } \\
\hline & 2010 & 2020 & 2030 & 2040 & 2050 & 2060 & 2070 & 2080 & 2090 & 2100 \\
\hline Russia & 12 & 12 & 12 & 12 & 12 & 12 & 12 & 14 & 16 & 17 \\
\hline EU28 & 73 & 76 & 77 & 77 & 78 & 78 & 81 & 86 & 92 & 95 \\
\hline North-America & 17 & 18 & 19 & 19 & 20 & 20 & 21 & 23 & 25 & 28 \\
\hline South-America & 10 & 11 & 11 & 11 & 11 & 12 & 12 & 15 & 19 & 23 \\
\hline Asia & 43 & 45 & 46 & 46 & 44 & 40 & 38 & 38 & 43 & 48 \\
\hline Africa & 18 & 18 & 18 & 18 & 17 & 16 & 17 & 19 & 23 & 28 \\
\hline World & 21 & 22 & 22 & 22 & 22 & 21 & 22 & 24 & 28 & 32 \\
\hline
\end{tabular}




\section{Sensitivity analysis}

The higher woody biomass use for energy has a relatively small effect on woody biomass material use in the baseline model, because the by-products and competition effects are small and they tend to cancel each other. The by-product effect is small, because the demand for final products is inelastic and roundwood can be used directly to energy without any limiations. The competition effect is small, because high availability of energy crops keeps the forest resources use low compared to their harvest potential.

To consider the sensitivity of by-products and competition effects we analyze three sensitivity scenarios, which are called sensitivity analysis 1, 2 and 3.

In the sensitivity analysis 1 , we increase the price-elasticity of final products demand from the baseline level (-0.1..- -0.5 based on Boungiorno et al. 2003) up to $-\infty$. The final products demand might become more elastic in the future, because woody biomass can potentially replace other materials, such as concrete, plastic or cotton (Menon and Rao 2012, Mallo and Espinoza 2014). More elastic demand increases the by-product effect, as it facilitates material production expansion.

In the sensitivity analysis 2 , roundwood use for energy is decreased $0-100 \%$ relative to baseline. Limiting roundwood use for energy is a subject that often arises in the debates around bioenergy. For example, in the EU there is an ongoing discussion concerning restrictions on roundwood use for energy to promote the cascading use of wood (Vis et al. 2016). Restricting roundwood use for energy increases the by-product effect, because byproducts demand for energy increases.

In the sensitivity analysis 3 , the availability of energy crops is decreased $0-80 \%$ relative to baseline. There are several uncertainties connected with large scale production of energy crops and it is unclear if energy crops can achieve their expected potential (Evans 1997, Searle and Malins 2014). Lower availability of energy crops increases the competition effect, as it leads to higher woody biomass use for energy.

For simplicity we keep the total biomass use for energy unchanged during the sensitivity analysis (Figure s1). Alternatively we could calculate new biomass use levels for the changed biomass availability by MESSAGE, but this would complicate the sensitivity analysis significantly, as chances in total biomass use for energy affect the substitution between fossil fuels and biomass. 


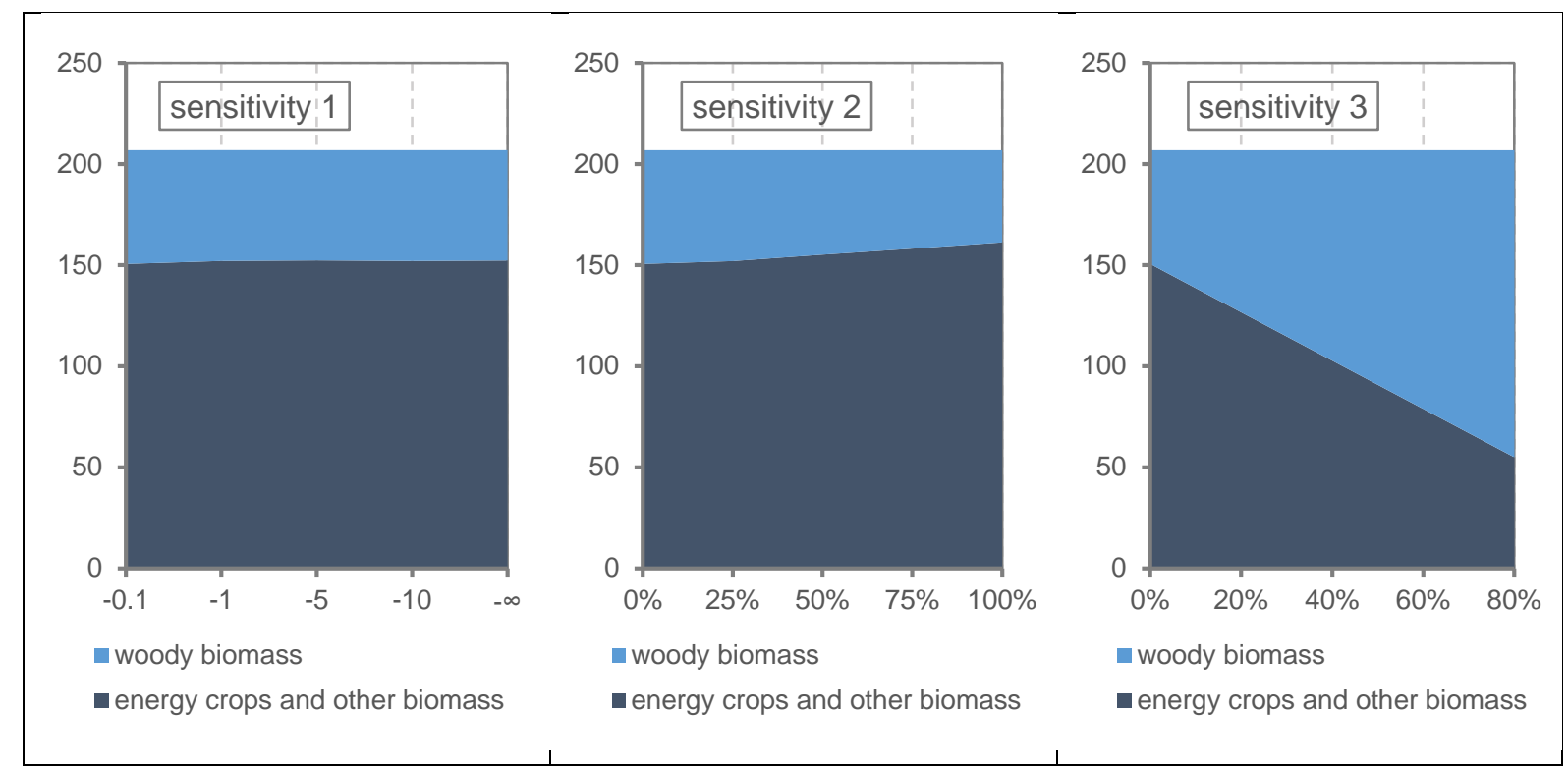

Figure s1: Biomass use for energy (EJ) in 2100 RCP2.6 for different sensitivity scenarios.

\subsection{Sensitivity analysis 1: More elastic demand for final products}

More elastic demand for final products demand leads to higher woody biomass material use (Figure s2). As consequence, there will be more by-products available for energy use, which decreases roundwood use for energy. If the price elasticity of final products is infinitely high (=fixed price demand) then the material use increases by $45 \%$ compared to baseline level in 2100 .

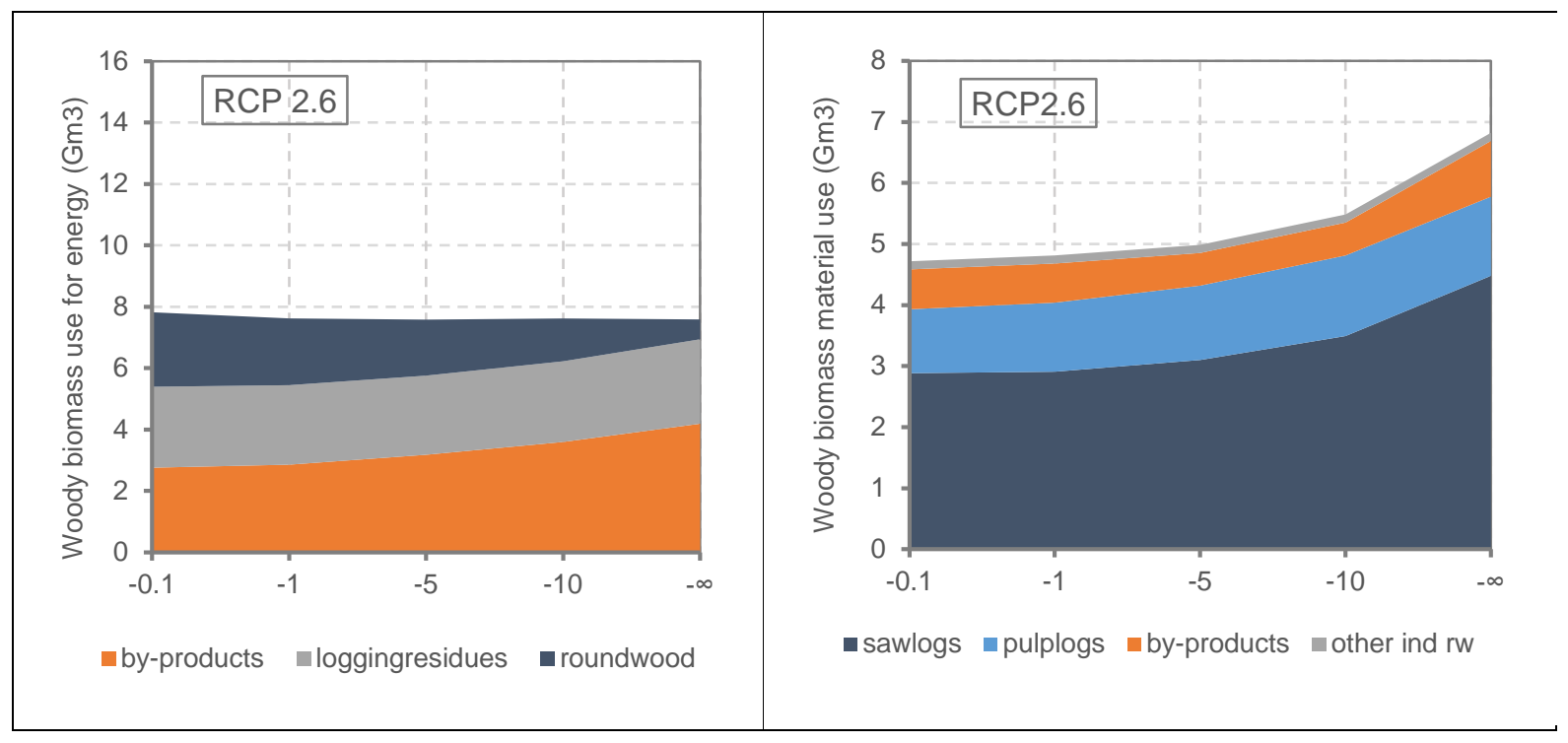




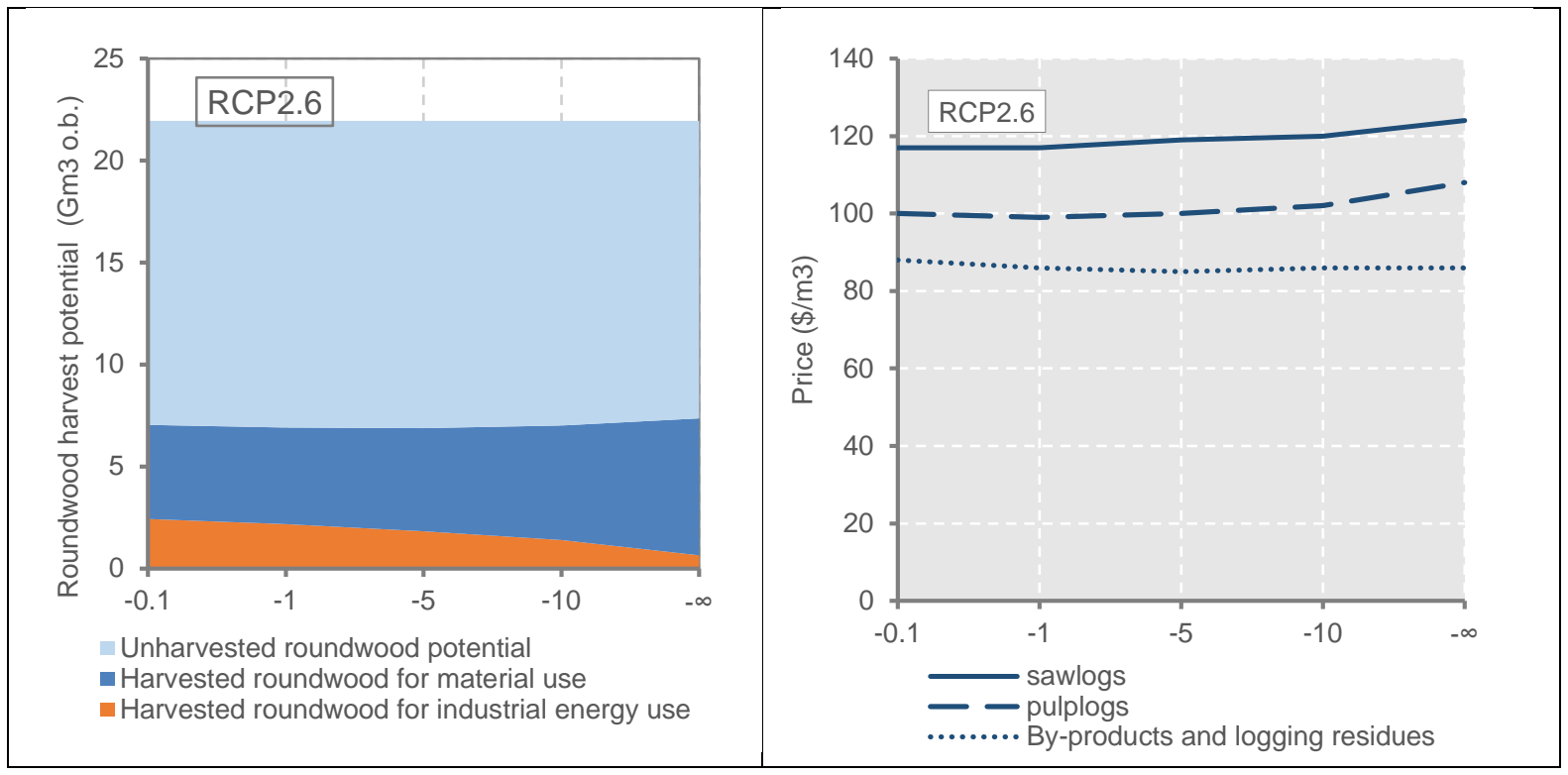

Figure s2: Woody biomass use for energy and material products, forest area and prices in 2100 RCP2.6 when the price elasticity of final products demand vary from -0.1 to $-\infty$.

\subsection{Sensitivity analysis 2: Restrictions on roundwood use for energy}

Restricting roundwood use for energy increases energy crops and by-products use for energy. The latter increases the by-products effect and leads to higher woody biomass material use (Figure s3). If roundwood use for energy is totally excluded then the material use increases by $15 \%$ compared to baseline in 2100 .

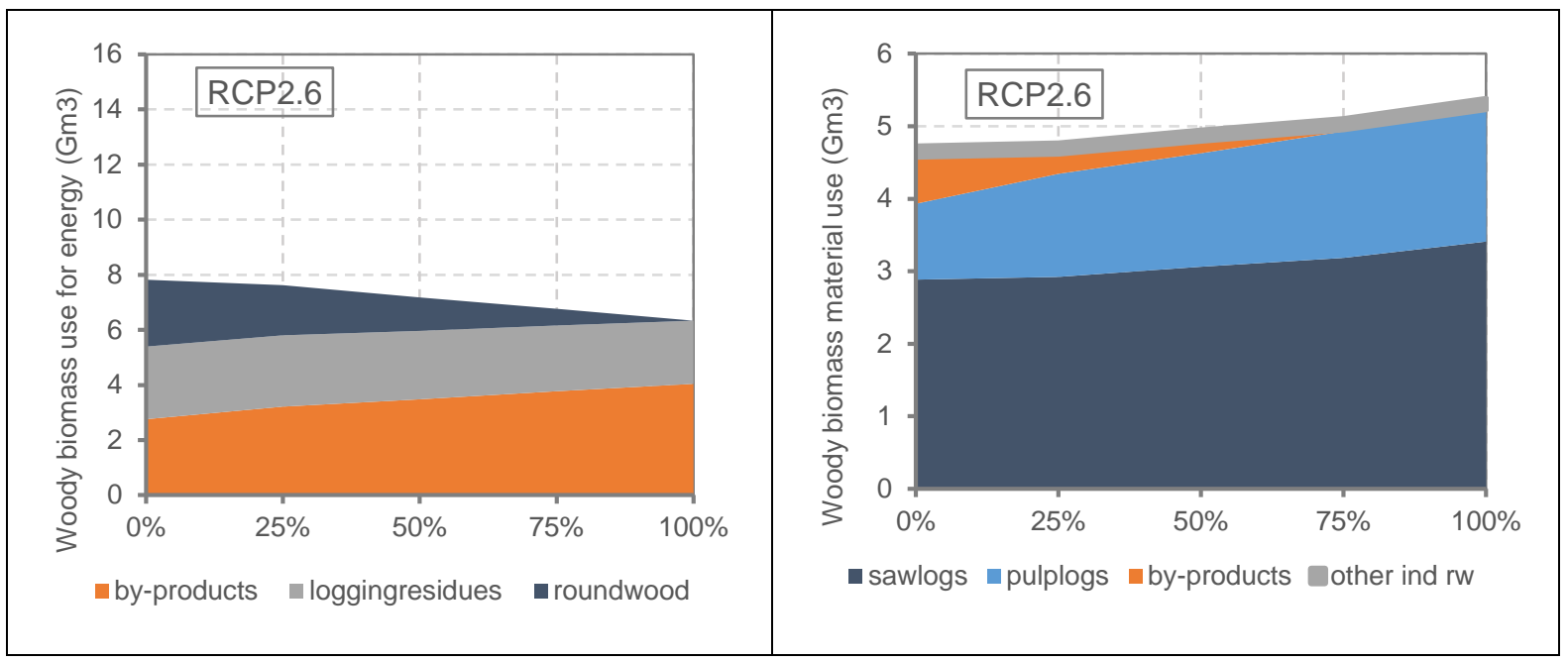




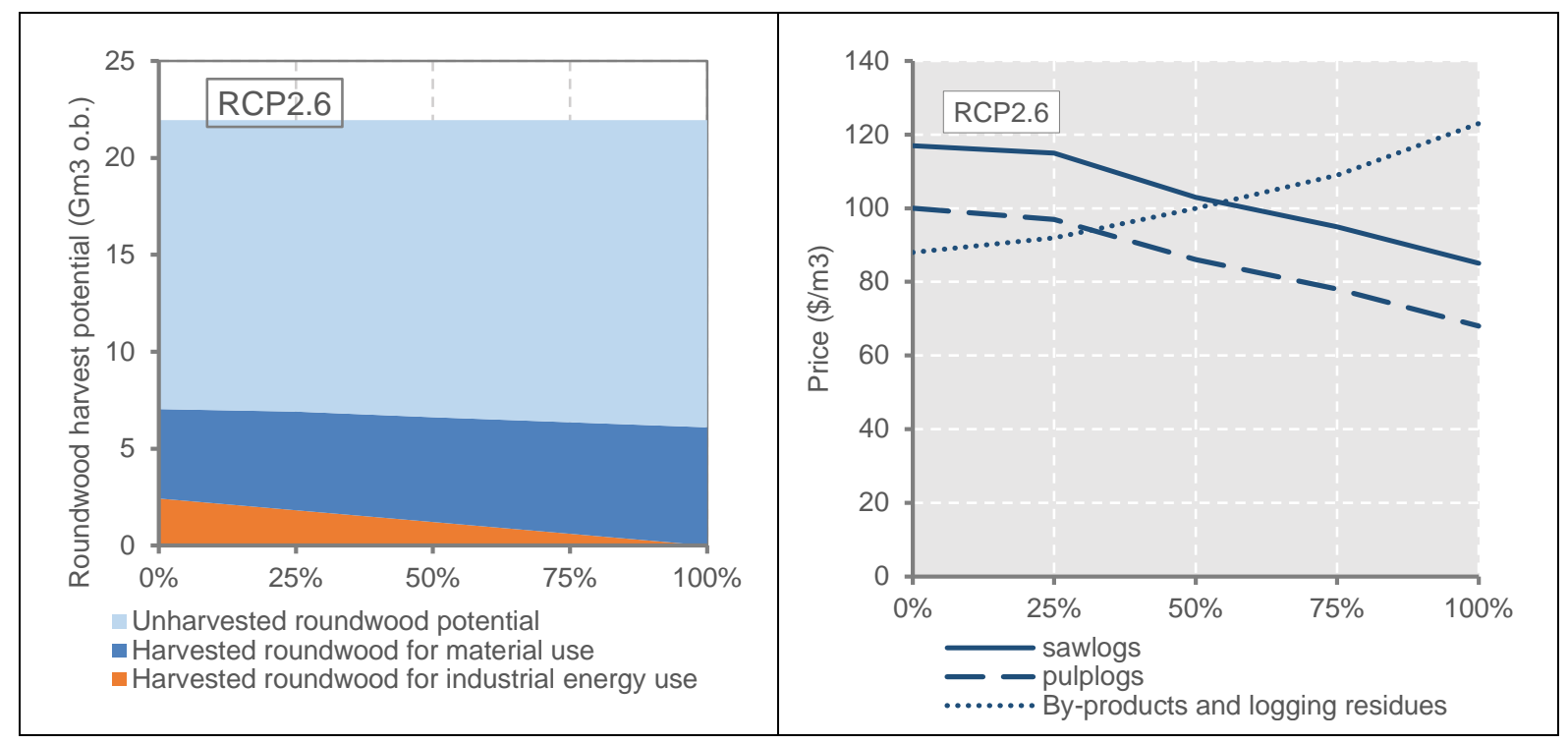

Figure s3: Woody biomass use for energy and material products, forest area and prices in 2100 RCP2.6 when roundwood use for energy is decreased $0-100 \%$ from the baseline level.

In Figure s3 we see that by-products and logging residues prices exceed rounwood prices when roundwood use for energy is restricted. The reason for low roundwood prices is the inelastic demand for final products, which allows the expansion of material production only if material final product prices and raw material costs are decreased. It is possible to maintain high by-products and logging residues prices, because roundwood control separates roundwood markets from energy markets and thereby eliminates arbitrage trading between the markets. In practise, it would be difficult to control roundwood use for energy if byproducts and logging residues prices exceed roundwood prices, because forest owners can transform roundwood to loggingresidues by chipping roundwood in the forest. For this reason, restricting roundwood use for energy would require sufficiently elastic demand for final products so that roundwood control would not lead to situation where by-products and logging residues prices exceed rounwood prices.

\subsection{Sensitivity analysis 3: Lower energy crops availability}

Lower energy crops availability increases roundwood use for energy (Figure s4). This leads to higher competition effect and lower woody biomass material use. If $80 \%$ of energy crops potential is excluded then the material use decreases by $20 \%$ compared to baseline in 2100 . 


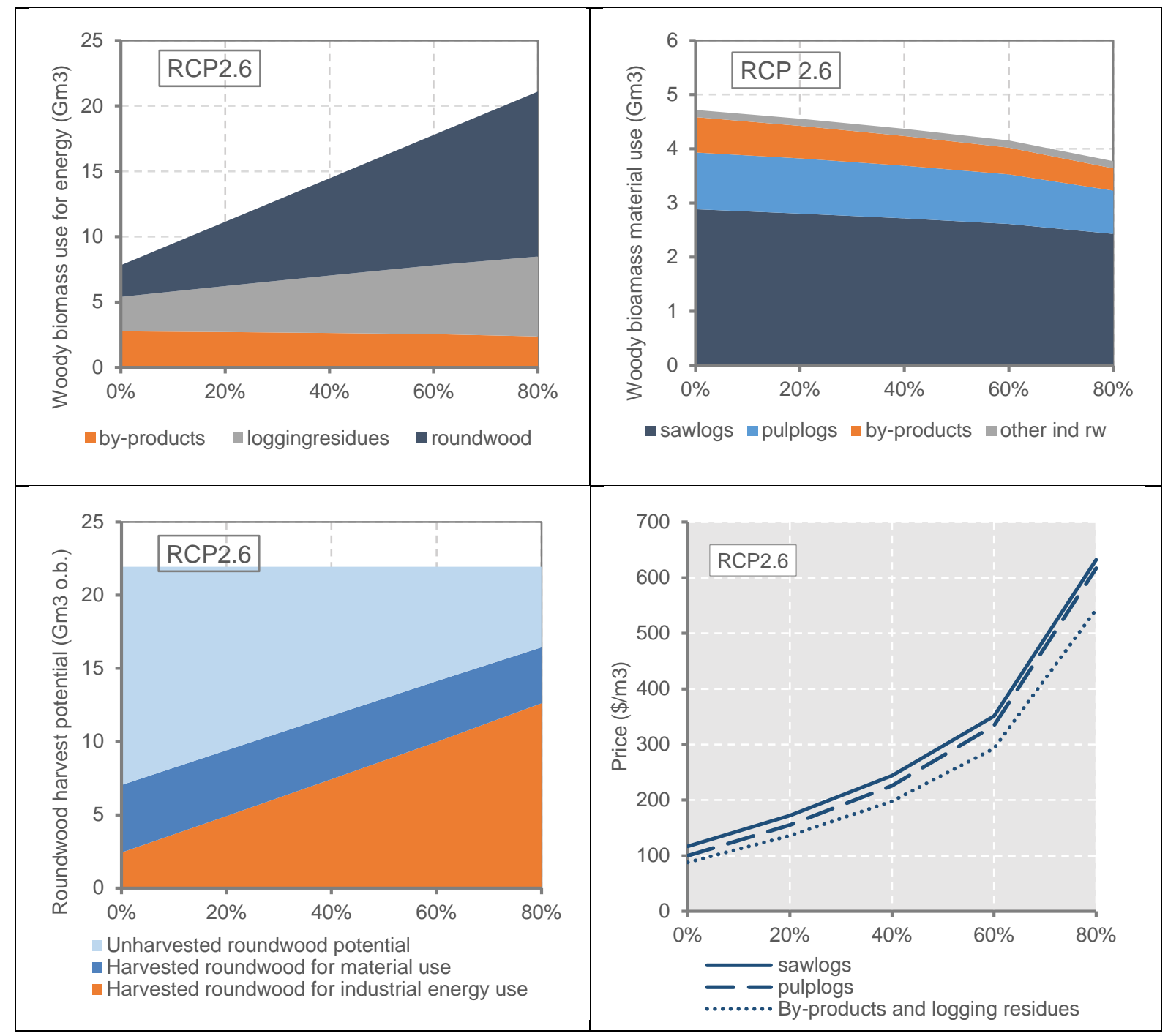

Figure s4: Woody biomass use for energy and material products, forest area and prices in 2100 for RCP2.6 when energy crops are decreased 0-100\% from the baseline level.

\section{References}


Buongiorno, J., Zhu, S., Zhang, D., Turner, J. and D. Tomberlin, 2003, The Global Forest Products Model, Elsevier.

Evans, J., 1997, Bioenergy plantations-experience and prospects, Biomass and Bioenergy 13, 189-191.

Gaulier, G. and S. Zignago, 2010, BACI: International trade database at the product level, CEPII working paper 2010-23.

Havlík, P., Schneider, U., Schmid, E., et al., 2011, Global land-use implications of first and second generation biofuels targets, Energy Policy 39, 5690-5702.

Havlik, P., Valin, H., Herrero, M., et al., 2014, Climate change mitigation through livestock system transition, Proceedings of the National Academy of Science, 111, 3709-3714.

IEA, 2005, Energy statistics manual, IEA report.

IPCC, 2006, Forest land, chapter 4 in IPCC Guidelines for National Greenhouse Gas Inventories.

Lauri, P., Havlik, P., Kindermann, G., et al. 2014, Woody biomass energy potential in 2050, Energy Policy 66, 19-31.

Mallo, M. and O. Espinoza, 2014, Outlook for cross-laminated timber in the United States, Bioresources 9(4), 7427-7443.

Menon, V. and M. Rao, 2012, Trends in bioconversion of lignocellulose: biofuels, platform chemicals \& biorefinery concept, Progress in Energy and Combustion Science 38, 522-550.

Searle, S. and C. Malins, 2014, Will energy crop yields meet expectations? Biomass \& Bioenergy 65, 3-12.

Vis, M., Mantau, U. and B. Allen, 2016, Study on the optimized cascading use of wood, Final Report, European Commission.

VTT, 2016, Properties of indigenous fuels in Finland, Technology research highlights 272, VTT Technical Research Centre of Finland. 